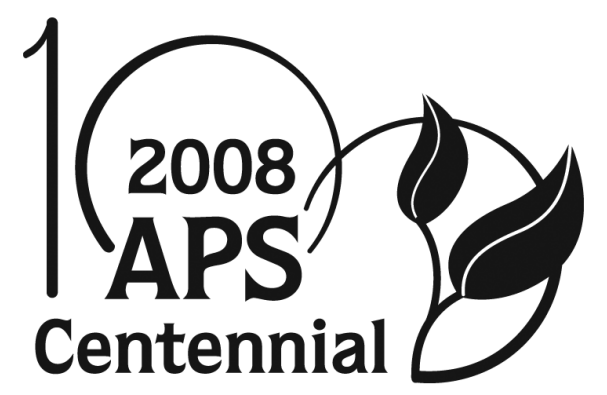

\title{
2008 APS Centennial Meeting Abstracts of Special Session Presentations
}

\section{Biology of Plant Pathogens}

\section{Aflatoxins, the Toxins that Redefined Plant Disease}

Significant features in the history of aflatoxins. J. Richard. Consultant to Romer Labs, Union, MO. Phytopathology 98:S182.

The discovery of aflatoxins began immediately after an outbreak of a disease of turkeys of unknown etiology in England in 1960. The disease was called Turkey " $\mathrm{X}$ " disease and was eventually attributed to a toxic groundnut meal imported from Brazil. From that point, an extensive effort to find the cause eventually elucidated that a species of mold, called Aspergillus flavus, was involved and the hepatotoxic products of this mold, found also as a component in the toxic groundnut meal, were called aflatoxins. The finding that the aflatoxins were carcinogenic caused concern for their occurrence in human foods and led to worldwide efforts to determine the relationships of these carcinogens to human disease and determine their occurrence in human foods as well as in animal feeds. The findings that the aflatoxins were immunosuppressive resulted in establishing that they were probable underlying causes to other diseases, mostly infectious in nature. Subsequent efforts led to the finding that aflatoxins can occur preharvest and therefore, the aflatoxins were no longer only a storage problem. Major crops such as corn, peanuts, cottonseed and certain tree nuts were frequently found to be contaminated. These findings were cause for the aflatoxin problem to become a large multidisciplinary scientific investigation into various aspects of concern such as eradication, control, analysis, epidemiology and plant pathology. Present day investigations with aflatoxins continue with elimination as a major thrust based on knowledge of the biosynthetic pathway, genetics of both host and pathogen, host-parasite-vector interactions, plant breeding, biocontrol and selected agronomic practices.

Epidemiological studies linking aflatoxin with human carcinomas throughout the world. J. Groopman. Bloomberg School of Public Health, Baltimore, MD. Phytopathology 98:S182.

Biomarker investigations have been extensively applied in the study of hepatocellular carcinoma (HCC), a major cause of cancer morbidity and mortality in many parts of the world, including Asia and sub-Saharan Africa, where there are upwards of 600,000 new cases each year. Much ( $80 \%)$ of the burden of HCC is manifest in the developing world. In a cohort study of over 18,000 people in Shanghai, a highly significant increase in the relative risk $(\mathrm{RR}=3.4)$ existed for those liver cancer cases where urinary aflatoxin biomarkers were detected. The relative risk for people who tested positive for hepatitis B virus (HBV) was 7.3, but individuals with both urinary aflatoxins and positive HBsAg status had a relative risk for developing HCC of about 59. These results strongly supported a causal, multiplicative relationship between two major HCC risk factors, HBV and AFB1 exposure. In many cases of HCC in China and Africa a double mutation in the HBV genome, an adenine to thymine transversion at nucleotide 1762 and a guanine to adenine transition at nucleotide 1764 (1762T/1764A), has been found in tumors. The onset of

The abstracts are published as submitted. They were formatted but not edited at the APS headquarters office. these mutations has been also associated with the increasing severity of the $\mathrm{HBV}$ infection and cirrhosis. Overall, there was an inverse relation between the $1762 \mathrm{~T} / 1764 \mathrm{~A}$ mutations in HBV and age at death, a finding that continues to confirm the predisposing nature of mutations in HBV detected in plasma samples up to 15 years prior to death.

Hierarchical levels integrating genetic and biochemical regulation of aflatoxin synthesis. N. Keller. University of Wisconsin, Madison, WI. Phytopathology 98:S182.

Since the first aflatoxin mutant generated in Aspergillus species in the 1970s to the identification of nuclear regulators of the aflatoxin gene cluster in recent years, our understanding of the molecular processes required for aflatoxin production has soared. Aflatoxin is a member of a chemical family known as polyketides where the carbon backbone of the metabolite is derived from a polyketide synthase (PKS), an enzyme bearing similarities to fatty acid synthases. The PKS generated aflatoxin backbone is further modified to the final molecule by numerous 'decorative' enzymes. All of the encoding enzymatic genes are clustered in a single genetic locus, which also contains an aflatoxin regulatory gene, aflR. AflR is a transcription factor required for expression of the enzymatic genes and is itself regulated by several parameters including signal transduction pathways, nuclear complexes and chromatin remodeling proteins.

Genomics, pathogenicity, and ecology of Aspergillus flavus. G. Payne. North Carolina State University, Raleigh, NC. Phytopathology 98:S182.

Aspergillus flavus is an opportunistic plant and animal pathogen as well as a producer of the carcinogen aflatoxin. Its genome size of $36.8 \mathrm{Mb}$ is larger than that for either A. nidulans or A. fumigatus, and is rich in predicted genes for secondary metabolism. Structural and functional genomics provide powerful approaches to identify candidate genes that condition pathogenicity and aflatoxin production in A. flavus. Comparative Genome Hybridization (CGH) between strains of A. flavus and A. oryzae, a closely related non-pathogenic species universally regarded as safe, revealed a small subset of genes unique to the two species. In a comparison among three strains of each species using an Affymetrix GeneChip expression microarray prepared for the sequenced strain of A. flavus, 43 and 129 genes were identify as unique to A. flavus and A. oryzae, respectively. In addition, polymorphism was found in only 607 genes between the two species. The same microarrays were used to monitor gene expression in A. flavus during infection of developing maize kernels. Over 160 genes were differentially expressed in developing maize seeds, including genes that have similarity to those known to be required for pathogenicity in other fungi. The small subsets of genes identified by structural and functional genomics likely contains members that contribute to pathogenicity and aflatoxin production in A. flavus.

Strategies to reduce aflatoxin contamination. P. Cotty. USDA ARS, Department of Plant Sciences, University of Arizona, Tucson. Phytopathology 98:S182.

In developed countries, human exposure to aflatoxins is reduced through government regulation. Regulations place unusual constraints on management of these plant diseases and these constraints change with crop, region, and 
intended market. In regions where foods are not monitored for aflatoxins, health concerns still dictate that aflatoxin exposure be minimized. Crops grown under conditions favorable for contamination become exposed to aflatoxin-producing fungi which are distributed throughout the environment. The contamination process may begin during crop development and continue until consumption and management must be directed at infection of both developing and mature crops. Physical damage caused by animals, stress, and severe weather predisposes crops to contamination. Insect control frequently reduces contamination but crops without insect damage may also become highly contaminated. Modification of cultural practices, use of less susceptible cultivars and biological control and post-harvest processing, storage, and detoxification can all contribute to producing commodities that may enter the most discriminating markets. Combinations of several controls are generally required to provide commercially acceptable management. In regions with severe perennial contamination, the most reliable solution remains planting crop species with reduced susceptibility.

\section{An Evolving Culture Collection System to Meet Modern Research Needs}

Prospects and pre-requirements of having a national plant pathogen collection system. R. Bennett. National Program Leader, USDA-ARS, Beltsville, MD. Phytopathology 98:S183.

The USDA Agricultural Research Service (ARS) possess hundreds of diverse microbial collections at research locations throughout the nation. These include various culture collections, specimen-based (non-living) collections, and non-organismal object collections. These collections play a variety of roles for scientific research. In 2007, ARS formed an ARS Collections Taskforce charged with assessing priorities for and stewardship of Federal scientific collections in ARS. As part of that activity, ARS scientists were requested to complete a survey form which included information on scientific collections and ancillary materials directly related to them. The goal of the ARS taskforce is to develop recommendations on how ARS can address the issue of stewardship of scientific collections. This survey supports the efforts of the APS Culture Collections Ad-hoc Committee. Results of the ARS culture collections survey and prospects for a national plant pathogen collection system will be presented.

Cereal rust urediniospore collections, history and future needs. A. Roelfs. Formerly Cereal Disease Lab, USDA-ARS, St. Paul, MN. Phytopathology 98:S183.

Since the early days of the 20th century rust studies have required cultures collections. Culture collections were maintained by scientists interested in breeding for resistance, Biffen 1907, and slightly later in studies of pathogen virulence, Stakman 1918. These studies used only a few cultures. The combined studies of resistance and virulence that resulted in the gene-for-gene theory (Flor 1947) required tens of cultures with different virulence patterns. Host lines with a single gene for resistance, Loegering 1969, made the initial studies of virulence in rust populations possible. More recently rust populations have been studied with various biochemical and genetic markers. Currently most of these collections were maintained by the various research projects involved. Possibilities now exist for studying the evolution (phylogeny) and the identity of the genes that control of the various parts of the life cycle of the rust fungi. These studies will require much larger collections of many more cultures worldwide and that include many rust species and genera. Large diverse collections can not be maintained by individual research projects. Such collections would require years to make with adequate a budget including consistency in funding and staffing. Each collection needs to be carefully and fully documented. These rust collections need to be backup with living host collections (seed) of the host plant or plants. Funding and maintenance by separate projects is unlikely to provide for such needs.
Microbial germplasm in seed banks and clonal repositories. F. Dugan. Western Regional Plant Introduction Station, USDA-ARS, Pullman, WA. Phytopathology 98:S183.

Seed banks and clonal repositories are sources of germplasm of higher plants, especially those of economic importance. However, they are also often sources of microbial germplasm for microorganisms that are consistently associated with propagative plant materials such as seeds, bulbs, cloves or cuttings. Obtaining plant germplasm as a source of endophytes, saprobes, or in certain cases even pathogens, may be cost effective when microbial isolates are unavailable or too costly in commercial culture collections. Moreover, seed banks and clonal repositories often house microbial collections used for research on plant germplasm. Such microbial collections are sometimes very extensive for one or more taxa of plant pathogens or other plant-associated microbes. Although seldom publicly cataloged nor offered for a fee, microbes from such collections may be distributed to qualified colleagues and collaborators at the discretion of curators or other personnel responsible for the microbial materials.

Unique features of maintaining collections of fastidious pathogens. $J$. Chen. USDA-ARS, Parlier, CA. Phytopathology 98:S183.

Culture collections are microbial-gene banks. The collections acquire and provide access to a wealth of information on microorganisms and their properties that are essential in enabling contemporary and future research in basic and applied sciences. Traditionally, culture collections mean that the microorganisms are maintained in a living form. This posts a particular challenge to the collections of fastidious prokaryotes, a group of bacteria that are difficult to isolate, culture and maintain even under the best known culture conditions. Examples of important fastidious plant pathogenic bacteria are: Xylella, Spiroplama, Phytoplasma, Candidatus Liberibacter, ect. While some of the bacteria can be cultured in complex media, others can only be maintained in Planta, making the collection of fastidious prokaryotes a more complicated issue as comparing to the collections of relatively easy-to-culture bacteria. Unique issues or problems associated with collections of fastidious plant pathogenic prokaryotes include: (1) Optimal culture storage methods are usually not available or not known. Strains could be more prone to be lost during the maintaining process; (2) This also bring up the issue of the need for better culture media and techniques; (3) Constant evaluation of culture purity and authenticity; (4) Impacts by regulations governing the safe handling, containment, classification of agents according to risk; (5) In vitro unculturable strains are maintained in experimental hosts under greenhouse conditions; (6) Requirements of high technical skills and specialized knowledge for culture curators.

\section{Assembling the Fungal Tree of Life: From Linnaeus to Deep Hypha and Beyond}

Fungal phylogeny: It takes a community. M. Blackwell. Louisiana State University, Baton Rouge, LA. Phytopathology 98:S183.

Fungi have a profound impact on global ecosystems. They modify our habitats and are essential for many ecosystem functions, e.g., soil formation, nutrient recycling, wood decomposition, plant growth enhancement, and plant culling from forests. Fungi feed us, poison us, parasitize us, and cure us. Some fungi may invade our bodies when our defenses are down; others cause allergy. Fungi destroy our crops, homes, and libraries. For practical and intellectual reasons it is important to provide a phylogeny for fungi upon which to base a stable classification. Working as a community, mycologists secured funding from the National Science Foundation [Research Coordination Networks in Biological Sciences: A Phylogeny for Kingdom Fungi (Deep Hypha), Assembling the Fungal Tree of Life 1 and 2 (AFTOL 1 and AFTOL 2)] to accomplish their objective. In addition to an ordinal level phylogenetic classification to retrieve information about 1.5 million species (Deep Hypha, AFTOL 1), the community continues to refine the classification (AFTOL 2).
A new Research Coordination Network: Fungal Environmental Sampling and Informatics Network (FESIN) will draw upon previous work to provide rapid identification tools for fungi.

Importance of subcellular structure in fungal phylogeny. D. McLaughlin. University of Minnesota, St. Paul, MN. Phytopathology 98:S183.

Morphological and anatomical characters can be misleading in establishing evolutionary relationships in Fungi. Subcellular structure continues to be systematically important and can provide shared, derived characters or synapomorphies for major fungal groups. To assess the state of knowledge of subcellular structure in fungi and fill gaps in the data, published and new ultrastructural studies are being brought together in the AFTOL Structural and Biochemical Database <aftol.umn.edu>. Characters available in the database include those for nuclear division, spindle pole body form and cycle, septum, and motile cells. Cystidium characters will be added, while Spitzenkorper and meiosporangium characters will be assembled for future addition. Inclusion of haustorial characters is desirable. Character states can be retrieved as NEXUS files for analysis in phylogenetic programs or used in tracing character evolution on existing phylogenies. Application of the data to current 
hypotheses for fungal phylogeny will be considered, and examples of what analysis of cystidium structure reveals about our understanding of this cell type will be discussed. With the rapid advances in knowledge of the fungi at the molecular level, attention needs to be refocused on cell structure to understand organismal function and adaptation.

The Ascomycota. C. Schoch, B. Robbertse, and J. W. Spatafora. Oregon State University, Corvallis, OR. Phytopathology 98:S184.

From Alternaria to Zygoascus and points in between, the Ascomycota is the largest fungal phylum, representing 33,000 or more species with numerous and diverse ecologies. As part of the Assembling the Fungal Tree of Life project (AFTOL), and in collaboration with numerous scientists across the globe the phylum was sampled broadly by sequencing six conserved marker genes. This resulted in a data matrix comprised of representatives of all of the currently accepted classes and more than $80 \%$ of orders. The phylogenetic framework resulting from analyzing these data was used to test hypotheses about evolution in morphology, development and ecology, as well as to identify novel, unclassified lineages. This framework will also be used to point towards areas that will be productive for the next generation of phylogenetics and phylogenomics.

The Basidiomycota. M. C. Aime. Louisiana State University, Baton Rouge, LA. Phytopathology 98:S184.

The Basidiomycota is the second largest phylum of Fungi, so-named because members produce their sexual spores externally on specialized cells termed basidia. Historically there has been considerable variation in the taxonomic ranks, groupings, and names applied within the basidiomycetes. This paper presents an overview of the consensus classification that resulted from community efforts spearheaded by the Assembling the Fungal Tree of Life (AFTOL) project and Deep Hypha RCN to provide a stable and phylogenetically based classification for all Fungi. Emphasis will be placed on highlighting changes in taxonomy and/or new classifications resulting from progress in phylogenetic reconstruction for those clades containing phyto- pathogenic basidiomycetes. For instance, Basidiomycota is now formally comprised of three subphyla: Pucciniomycotina (= Urediniomycetes, or rusts and their allies); Ustilaginomycotina (smuts and their allies); and Agaricomycotina (= Hymenomycetes, or the mushroom-forming fungi and their allies), all of which contain economically important plant pathogens. Other changes include the placement of Mixiomycetes, fern parasites originally described in the Ascomycota, within Pucciniomycotina and confirmation that the Microbotryomycetes, or "anther smuts" belong within Pucciniomycotina and not with the true smuts in Ustilaginomycotina.

The Oomycota. C. A. LÉVESQUE (1), A. W. A. M. de Cock (2), G. Robideau (1), N. Desaulniers (1), and K. Bala (1). (1) Agriculture and AgriFood Canada, Ottawa, ON, Canada; (2) Centraalbureau voor Schimmelcultures, Utrecht, The Netherlands. Phytopathology 98:S184.

Oomycetes are no longer part of the Eumycota, or true fungi. Although oomycetes are different from true fungi in many ways, the two groups still have many common ecological features. Molecular taxonomy and phylogenies have confirmed for the most part the traditional classification of oomycetes. The two main orders of Saprolegniales and Peronosporales are still well separated by phylogenies. Most important plant pathogen genera such as Pythium and Phytophthora are still monophyletic and their species morphological taxonomy is generally supported by molecular analyses. There are a few exceptions though. There are some species that are being split (e.g. Py. irregulare), genera that are within a genus clade (e.g. Pythiogeton), and clades that might require a new genus status (e.g. Pythium vexans clade). Most phylogenetic studies of oomycetes have been done with the ribosomal DNA cistron and mitochondrial cytochrome oxidase genes but multigene phylogenies were performed in Phytophthora. These were made possible by the large amount of genome sequence information available for different species of this genus. The genome of Pythium ultimum was recently sequenced, opening new possibilities of multigene studies in Peronosporales. There are also efforts to sequence the genome of Saprolegnia parasitica which would greatly facilitate broader phylogenetic studies in oomycetes.

\section{Down in the Dirt with Phytopathogenic Verticillium: Genetic and Molecular Tales of a Vascular Fungus}

Significance and life history of phytopathogenic species of Verticillium. R. C. Rowe. Ohio State University, Wooster, OH. Phytopathology 98:S184.

Infection by Verticillium causes major losses in economically important agronomic crops (cotton, alfalfa, mint, oilseed rape, hops), vegetables (potato, tomato, cauliflower, lettuce, melons), fruit (strawberry, brambles, grapes), tree fruit (olive, almond, avocado), and shade trees (maple, ash). Verticillium causes vascular wilt, but symptoms vary to include general or partial wilting, stunting or slow decline. The primary pathogens are V. albo-atrum and $V$. dahliae, species that occur worldwide in temperate regions, the former where soil temperatures remain $<25^{\circ} \mathrm{C}$. Recently a third species, $V$. longisporum, has been identified as an important pathogen of brassicaceous crops. The genus is named for characteristic verticilliate conidiophores. Microsclerotia ( $V$. dahliae and $V$. longisporum) or melanized hyphae (V. albo-atrum) survive many years in soil. Root exudates trigger germination and infection occurs at or just behind root tips. Conidia form in vascular tissues and are transported in xylem vessels resulting in systemic infection. Microsclerotia or melanized hyphae form in senescent tissues and are released into soil, completing the monocyclic disease cycle. The pathogen is widely disseminated through infected propagative material such as tubers, crowns and rhizomes. Host-adapted strains exist within Verticillium species. Distinct vegetative compatibility groups have been identified within $V$. dahliae that correlate well with strains highly aggressive to particular hosts.

The molecular road from differentiation of Verticillium isolates to analysis of growth and development. K. F. Dobinson. Agriculture \& AgriFood Canada, London, ON, Canada. Phytopathology 98:S184.

The recent history of molecular research on phytopathogenic Verticillium species began with studies of isolate differentiation and the development of DNA-based detection methods. Virtually all of the molecular tools subsequently developed for Verticillium dahliae, V. albo-atrum and V. longisporum, and which will be referred to here, have been borrowed and/or adapted from those used for a variety of organisms, primarily other filamentous fungi, as well as yeast and plants. Our initial studies focused on analyses of genetic diversity, using both molecular and biological characters (DNA fingerprints, vegetative compatibility groups, and race types) to differentiate $V$. dahliae isolates and to investigate genetic variation among isolates from North American tomato fields and potato seed tubers. More recently, we have used EST and small-scale microarray analyses to identify genes expressed during i) growth of $V$. dahliae in a simulated xylem fluid medium, and ii) development of $V$. dahliae microsclerotia (MCS), the longlived, melanized resting structures that form in the very late stages of the life cycle and are well able to survive adverse field (and laboratory) conditions. In order to begin to asses the potential roles of these genes in pathogenicity and/or resting structure development, an efficient Agrobacterium tumefaciensmediated gene replacement system was exploited for gene disruption. The results of these experiments indicated that several of the genes which had been disrupted were needed for MCS or dark resting mycelial development in $V$. dahliae and $V$. albo-atrum, respectively. To further investigate the corresponding developmental pathways, functional characterization has been initiated for these genes, including the orthologous class II hydrophobin genes in $V$. dahliae and V. albo-atrum (Vdh1 and VaVdh1, respectively), and most recently, a gene with high similarity to the yeast autophagy gene $A T G 8$.

Arabidopsis-Verticillium interaction as a model disease system. P. Veronese. North Carolina State University, Raleigh, NC. Phytopathology 98:S184.

Most of our understanding of plant defense against pathogens has come from studies with microorganisms causing foliar diseases. To contribute to the elucidation of the molecular genetics of host resistance against systemic invaders, we are studying the interaction of the model plant Arabidopsis thaliana with the soil-borne fungus Verticillium longisporum, causal agent of vascular diseases of cruciferous and non-cruciferous crops worldwide. We have found that in Arabidopsis, like in other plant species, $V$. longisporum infection induces disease symptoms by interfering with the host developmental program. In particular, the pathogen causes early flowering, accelerated senescence and rapid death in the susceptible accession Columbia, whereas, it extends vegetative growth and causes only mild chlorosis in the more tolerant accession C-24. Via forward genetics, we isolated mutants of C24 with altered disease phenotype and identified three independent loci, VERTCILLIUM HYPERSENSITIVE (VHS) 1 to 3, able to convey increased tolerance likely functioning as negative regulators of the pathogen-induced transition to flowering and/or senescence syndrome. The vhs 3 mutation was linked to disruption of AtBRM, coding a SNF2 chromatin remodeling protein. We will present data characterizing pleiotropic effects of vhs mutations on Arabidopsis defense responses and development. Furthermore, we will discuss results from genome-wide transcriptional analysis upon pathogen challenge, providing new insights on signaling pathways controlling basal defense mechanisms. 
Functional analysis of tomato responses to Verticillium dahliae. B. Thomma, U. Ellendorff, P. van Esse, R. de Jonge, G. van den Berg, K. Yadeta, S. Rehman, and E. Fradin. Wageningen University, Wageningen, The Netherlands. Phytopathology 98:S185.

Verticillium dahliae is a soil-borne vascular pathogen of over 200 dicot plant species that include tomato. In our lab we have also established a successful soil-based $V$. dahliae-infection assay for Arabidopsis. Previously, from Verticillium-resistant tomato the so-called Ve locus was cloned that comprises two resistance gene analogs that encode receptor-like proteins (RLPs). RLPs are composed of extracellular leucine-rich repeats that are anchored in the plasmamembrane and only have a short cytoplasmic tail that lacks obvious signaling motifs. In our lab, we try to uncover the function of RLP-type disease resistance genes in Arabidopsis and tomato. In the Arabidopsis genome, 57 RLP-encoding genes (AtRLP genes) have been identified of which only $C L V 2$ and $T M M$ have previously been characterized. Both genes play a role in plant development through maintenance of stem cell populations and stomatal distribution, respectively. A knock-out collection for the 57 AtRLP genes was assembled and screened for altered susceptibility towards various microbial pathogens including Verticillium. In order to study defense signaling downstream of RLPs, we aim to unravel the signaling cascade that is activated by the $V e$ resistance proteins in tomato upon detection of Verticillium presence. Diverse candidate genes are assessed for their role in $V e$-mediated resistance signaling. Furthermore, through diverse approaches we aim to characterize and study the effector catalogue of in planta-secreted Verticillium proteins. In this way, we not only hope to uncover virulence factors of Verticillium, but also expect to identify the Verticillium effector that is recognized by the Ve proteins.
Verticillium comparative genomics: Understanding pathogenicity and diversity. S. J. Klosterman (1), P. Veronese (2), K. F. Dobinson (3), K. Subbarao (4), D. I. Heiman (5), S. Young (5), C. D. Kodira (5), L. Alvarado (5), J. Galagan (5), B. Birren (5), C. Cuomo (5), A. Anchieta (1), S. Kang (6), S. E. Gold (7), and L.-J. Ma (5). (1) USDA-ARS; (2) North Carolina State University; (3) Agriculture and Agri-Food Canada; (4) University of California Davis; (5) Broad Institute of MIT and Harvard; (6) Penn State University; (7) University of Georgia. Phytopathology 98:S185.

Verticillium dahliae is the primary causal agent of Verticillium wilt that causes billions of dollars in annual losses worldwide. This soil-borne fungal pathogen exhibits extraordinary genetic plasticity, capable of colonizing a broad range of hosts in diverse ecological niches. Moreover, $V$. dahliae can survive in the soil for up to 15 years as melanized microsclerotia, which makes the control of Verticillium wilt particularly difficult. One factor that has hindered progress in developing new control strategies for Verticillium wilt is our limited understanding of the biology and ecology of $V$. dahliae and related pathogens. We are employing a genomic approach to compare it to a closely related species $V$. albo-atrum that has distinct phenotypes with respect to pathogenicity and exhibits host range differences. A 7.5X assembly of the $33.8 \mathrm{Mb}$ genome of a lettuce isolate of $V$. dahliae is now publicly available via the Broad Institute. This genome assembly was anchored to eight chromosomes via an optical map ( 300X physical coverage). About 37,000 EST reads from three cDNA libraries of $V$. dahliae have been generated. A $4 \mathrm{X}$ assembly of an alfalfa isolate of $V$. albo-atrum is being prepared. We will report the progress of genome sequencing and annotation for these two Verticillium spp. and discuss notable genome features in the contexts of their distinct biology.

\section{Disease of Plants}

\section{A Century of Turfgrass Pathology, Then, Now, \& The Future}

History of the turfgrass pathologist and contributions from the beginning to 1980. J. M. Vargas Jr. Michigan State University, East Lansing, MI. Phytopathology 98:S185.

Turfgrass pathology began to flourish after World War II. The first noted turfgrass pathologist was Dr. Frank Howard at the University of Rhode Island. Others who followed included Dr. Malcolm Shurtleff, University of Illinois; Dr. Charles Gould, Washington State University; Dr. T. E. "Ed" Freeman, University of Florida; Dr. R. W. Toller, Texas A\&M University; and Dr. Gayle Worf, University of Wisconsin. Their research responsibilities included other crops in addition to turfgrass. The first full time turfgrass pathologist was Dr. Houston Couch at Penn State University He was followed by Dr. Herbert Cole, Jr., Penn State University; Dr. Noel Jackson, University of Rhode Island; and Dr. Joseph M. Vargas, Jr., Michigan State University as full time turfgrass pathologists. Many important advances were made during this era including the discovery of Fusarium blight, later divided and renamed summer patch and necrotic ring spot. In addition, a fungus was shown to cause spring dead spot; the first important viral disease of turfgrass, SAD on St. Augustine grass, was discovered; and anthracnose and other diseases were identified as the cause of death of annual bluegrass rather than heat, as was previously believed. Dr. Couch published the first turfgrass disease book entitled "Turfgrass Diseases". Informal turfgrass pathology evening sessions at APS were started in the 1950 's where anyone could present their latest findings.

Turfgrass pathology from 1980 to today. B. B. Clarke. Rutgers University, New Brunswick, NJ. Phytopathology 98:S185.

The 28 year period following 1980 has been a time of great change in the field of turfgrass pathology. Knowledge of soilborne pathogens increased rapidly with the development of improved isolation and detection techniques. At least five new patch diseases and their causal agents, some newly described, have been reported since 1984. Studies focusing on the biology, taxonomy, epidemiology and detection of foliar and root-infecting fungi during the past two decades have greatly expanded our understanding of these pathogens and the diseases that they cause. Advances in biotechnology have resulted in the development of methodologies that greatly improved our ability to detect and identify turf pathogens. For example, immunoassays were first marketed for the detection of turf diseases in 1986. Later, molecular tools such as DNA probes, PCR-based fingerprinting and DNA sequencing were used to clarify phylogenetic relationships, identify species and define population structure for many turf pathogens and their hosts. In the 1980s, bacterial wilt, necrotic ring spot, pink patch, summer patch and yellow ring were identified. This was followed by the discovery of bermudagrass decline, dead spot and gray leaf spot (on perennial ryegrass) in the 1990s and, most recently, reports of brown ring patch, kikuyugrass decline, rapid blight and yellow spot. Within the past decade, anthracnose and dollar spot have reemerged as major diseases on golf courses in the North America.

What does the future hold for turfgrass pathology? L. Tredway. North Carolina State University, Raleigh, NC. Phytopathology 98:S185.

Turfgrass pathology is an integrated discipline, and historically its evolution has been closely tied to advances in microbiology, plant pathology, agronomy, agricultural engineering, plant breeding, and agrochemistry. Changes in the discipline will continue to be driven by these forces. Emerging technologies in precision agriculture will allow implementation of management practices with unprecedented accuracy. An understanding of how cultural practices impact disease development is needed so that these tools can be used effectively. Methods for remote detection of disease symptoms may also enable precision application of fungicides. As freshwater resources become more limited, the potential impact of water quality on disease development must be investigated. Turfgrass breeders are beginning to focus on disease resistance in important grass species. Studies of functional genomics and host-parasite interactions may identify resistance genes for integration into turfgrass cultivars using traditional or transgenic techniques. Due to the site-specific nature of new pesticide chemistries, fungicide resistance will continue to be an important issue. We must develop an understanding of how pathogen populations are structured and how they respond to selection forces in order to identify strategies that will prevent or delay fungicide resistance.

\section{Detection, Identification, and Diagnostics: Advancing the Science One Sample at a Time}

An historical perspective on plant disease diagnosis. G. Hudler. Cornell University, Ithaca, NY. Phytopathology 98:S185.

It stands to reason that the history of plant disease diagnosis should not have begun until people knew that something other than foul ether caused plants to grow poorly. And so it is that we traditionally point 1807 and the classic work of Benedict Prevost and his correct observation that bunt of wheat was caused by a pathogenic microbe as a convenient starting point. For the next 150 years, fungi as causal agents of plant disease held center stage, with occasional diversions by discoveries that nematodes (Berkeley), bacteria (Burrill), and viruses (Ivanowski) also caused unwanted maladies. Correct diagnoses depended on critical evaluation of symptoms, microscopic exam of 
diseased tissue and putative pathogens. With improved technology, new groups of pathogens (e.g. viroids, phytoplasmas, fastidious prokaryotes) have been discovered and identification of "old" pathogens has become less subjective with the advent of nucleic acid sequencing, improved immunologic tests, and other techniques for distinguishing microbial taxa. However, the history of plant disease diagnosis is not just about microbes, and one must also account for the crucial role that diagnostician's play in identifying the wide array of plant maladies caused by non-infectious agents. Thus, the discovery and elucidation of the role of mineral nutrients, soil chemistry, air pollutants, herbicides, and some transient (e.g. potato leafhoppers) or extraordinarily small (e.g. eriophyid mites) arthropods are equally important historical milestones. With the prospects of increasingly abrupt weather fluctuations on the horizon, the diversity of plant problems to challenge future diagnostician is sure to be larger and more formidable.

Fungal ID through the years. M. E. Palm. USDA/APHIS/PPQ, Beltsville, MD. Phytopathology 98:S186.

The identification of fungi has long been a challenge. Fungi are a large and diverse group occurring in or on all living substrates, often with two or more morphologically distinct stages. Morphology in vivo and in vitro has been and still is a key character for identifying many fungi. Tools include published keys, descriptions and the more recent web-based interactive keys. Some of the first non-morphological means for distinguishing taxa were genetic differences such as mating type, vegetative incompatibility, and anastomosis groups. Isozyme analysis and biochemical characters such as secondary metabolites have been used successfully to distinguish some groups of fungi. Molecular methods have provided another set of tools for identifying fungi, especially those taxa that do not grow in culture, are morphologically indistinguishable, or are difficult to differentiate using other techniques. Sequences are from well-characterized specimens provide a very useful tool for identifying taxa. The Barcode of Life initiative envisions the use of a unique segment of the genome to rapidly identify a species, ideally using a portable barcode reader. For all methods from morphology to fingerprinting, the identification is only as accurate as the taxonomic knowledge of the group based on robust systematics studies utilizing all available characters.

Plant virus ID - The first 100 years. C. Sutula. Agdia, Inc., Elkhart, IN. Phytopathology 98:S186.

Nearly everything known about plant viruses has been discovered and developed in the last 100 years. It is an exciting story of discovery in science with revolutionary impact on the way we view and understand life processes. A direct result from this work is that we now have a variety of methods to detect and identify plant viruses reliably and quickly. This presentation will highlight and discuss those methods that have been accepted as practical and effective. It will also explain how the methods became estab- lished and speculate on the nature of the methods that may be available in the near future.

Bacterial plant pathogens: Traversing a century of change. A. Alvarez. University of Hawaii, Honolulu, HI. Phytopathology 98:S186.

A century ago bacteria had just begun to gain recognition as bona fide plant pathogens. Although the etiology of fire blight, hyacinth yellows, crown gall, soft rot, and olive knot diseases had been described by American and European scientists, it wasn't until 1901, when Erwin F. Smith completed a series of controversial exchanges with Emil Fisher, that bacteria were more widely recognized as causal agents of plant disease. This initiated an era of disease diagnosis and bacterial identification based primarily on physiological, biochemical and pathogenicity tests. Immunodiagnostics, metabolic profiling, fatty acid analysis and the use of selective media were later added to the battery of diagnostic tests. In parallel, DNA-based methods were developed to unravel phylogenetic relationships among known species and examine diversity at the subspecific level. This talk highlights some of the key discoveries that permit the current practitioner to detect and identify plantassociated bacteria.

Plant disease diagnostics and forensic science. N. Barnaby, A. Giusti, and B. Budowle. FBI Laboratory, Quantico, VA. Phytopathology 98:S186.

Biological terrorism directed at disruption of agriculture could have devastating effects on the nation's ability to provide for its population and could have a massive impact on the national economy. In cases of deliberate release, the capability of laboratories to characterize the causal agent and provide additional analysis will be an important component of the criminal investigation. Microbial forensics is a recently developed discipline that seeks to derive as much information as possible from microbial agents used during a biocrime. For forensic purposes, one of the most valuable tools is the genetic analysis of the pathogen to detect variations that may provide investigative leads or attribution data. Current methods for the genetic characterization of microbial pathogens include various forms of sequence variation analysis, such as length polymorphisms, genetic rearrangements, or single nucleotide polymorphisms (SNPs). However, in order to obtain the most information about an organism, it may be necessary to survey the entire genome sequence of an organism. High throughput sequencing, as represented by advances in pyrosequencing and through the use of microarrays are approaches that can speed analyses and potentially aid a criminal investigation. Programs and initiatives designed to augment the forensic capabilities of agricultural testing laboratories must continue to look for new technologies to aid in the investigation. However it is important that the methodologies and approaches developed for forensic purposes are capable of meeting the admissibility requirements of the U.S. legal system.

\section{Faces of the Future in Mycology-A Look to the Future}

Genomic and proteomic approaches for dissecting host - pathogen interactions. T. K. Mitchell. Department of Plant Pathology, The Ohio State University, Columbus, OH. Phytopathology 98:S186.

Over the past decade, the development of genome based technologies has revolutionized large-scale biology and revealed the genome content of a rapidly growing number of organisms. Now the challenge is to understand the function and regulation of identified genes within the context of an organism's biology and life style. For the rice blast pathosystem, we are fortunate to have a completed genome sequences for both rice and Magnaporthe grisea, the causal agent of rice blast disease. Few pathosystems rival rice blast for its impact on human nutrition, the sophistication of molecular and classical genetic tools available for research, and its amenability to laboratory manipulation. Using a bioinformatics approach, we have annotated 595 genes predicted to function directly as transcription factors or in support of transcriptional activity. cDNA from $>80 \%$ of these predicted genes were cloned and their proteins expressed in yeast. The proteins were subsequently spotted on glass slides to generate the $M$. grisea transcription protein array. The chip was hybridized with kinases known to be involved in infection structure formation to identify their targets for phosphorylation. This talk will detail the identification and functional characterization or transcription factors required for successful infection and the genes they regulate.

Current challenges in fungal systematics: Defining natural groups in the Ascomycota. P. Chaverri. Department of Biology, Howard University, Washington, D.C. Phytopathology 98:S186.

Defining genera and species in fungi, especially in the Ascomycota, is a constant challenge. The Ascomycota is an especially difficult group because its members are generally very small, and have anamorphs that are completely different from their teleomorphs. In addition, most species grow and reproduce asexually for most of their lives. Because precise taxon identification is necessary for other research and applied areas, delimiting genera and species is a basic and essential task for mycologists. My research focuses in defining genus and species concepts in economically important genera in the Hypocreales, such as Hypocrea (anamorph Trichoderma), Hypocrella (anamorph Aschersonia), Nectria sensu lato (anamorphs Fusarium, Tubercularia, Cylindrocarpon, etc.), and fungal endophytes of the rubber tree Hevea brasiliensis. My research analyzes a combination of multiple characters, morphological and molecular, to elucidate phylogenetic relationships and define genera and species.

Occurrence, aggressiveness, somatic growth and reproduction of phenylamide-resistant and -sensitive oomycete pathogens. L. D. Porter. USDA-ARS, Prosser, WA. Phytopathology 98:S186.

Pink rot of potato, caused by Phytophthora erythroseptica, is a major field and post-harvest problem in Idaho, particularly since 1998 when isolates resistant to the phenylamide fungicide metalaxyl-M were detected. Isolates of $P$. erythroseptica were collected from infected tubers in 2001 and 2002 from six Idaho counties and tested for resistance to metalaxyl-M on amended agar. Metalaxyl-M-resistant (MR) and metalaxyl-M-sensitive (MS) isolates were identified in six counties; 160 isolates were highly resistant, seven moderately resistant and 57 sensitive to metalaxyl-M with mean EC50 values of 182, 23 and $0.5 \mathrm{mg} \mathrm{L}-1$ of metalaxyl-M, respectively. Mycelial growth rates and oospore production in agar were assessed for $20 \mathrm{MS}$ and $20 \mathrm{MR}$ isolates at 10, $15,20,25$ and $30^{\circ} \mathrm{C}$. Growth rates of MR isolates were between 2.5 and 3.1 times greater than those of MS isolates at $10,15,20$ and $25^{\circ} \mathrm{C}$, and oospore production was between 6.8 and 20.5 times greater for MR than for MS isolates at the same temperatures. Colony growth in $\mathrm{V} 8$ broth at $18^{\circ} \mathrm{C}$ was 
greater for MR than for MS isolates. However, zoospore production at $18^{\circ} \mathrm{C}$ was greater for MS than for MR isolates, and zoospore production mm-1 of colony circumference was also greater for MS than for MR isolates, 14,191 and 9,959 , respectively. Rate of growth through tuber tissue was significantly different for resistant and sensitive isolates at $3.3^{\circ} \mathrm{C}$ but not at $7.2,10,15,20$, and $25^{\circ} \mathrm{C}$, although growth of resistant isolates was numerically greater at all temperatures. Sexual reproduction of MR isolates in nature may be greater than MS isolates, but MS isolates may be more asexually fit. Current research is addressing the wide-spread occurrence of phenylamide-resistant isolates of Pythium ultimum in the Pacific Northwest.

Application of real-time PCR for the study of Pythium and Rhizoctonia ecology. K. L. Schroeder. USDA-ARS, Root Disease \& Biological Control Research Unit, Pullman, WA. Phytopathology 98:S187.

Pythium and Rhizoctonia are common pathogens of cereals in eastern Washington, causing damage virtually everywhere these crops are grown. However, each of these genera has multiple species or AG groups which may be present in multiple combinations. Techniques for quantification of these pathogens to relate pathogens numbers with disease severity is a complex task. Traditional culture-based quantification methods are tedious and sometime inaccurate, and do not reflect the total diversity of a pathogen group. With variation in virulence and geographic distribution throughout the state, it is important to know which species are present and in what quantity. Species-specific primers were designed for 10 species of Pythium and 6 AG groups or species of Rhizoctonia. These primers were used with real-time PCR in combination with a soil DNA extraction process to develop a procedure to detect and quantify selected species from soil samples. A survey of fields over a wide geographic area was conducted in 2006 and 2007. Population data obtained for the different Pythium and Rhizoctonia spp. has revealed interesting correlations between the occurrence of particular species in relation to rainfall and possibly the type of crop rotation. As more data is collected, the use of this technique will spread more light on the ecology of these pathogens and these tools may one day be useful for pre-plant testing of soils to determine disease risk.

\section{If We Had Known Then What We Know Now: Reflections on Catastrophic Tree Diseases}

Oak wilt; did our response match the threat? D. Appel. Texas A\&M University, College Station, TX. Phytopathology 98:S187.

The discovery of oak wilt in the upper Midwest in the early 1940s was met by the U.S. forestry community with a great deal of concern. The pathogen, Ceratocystis fagacearum, resembled several recently introduced exotic forest pathogens and there was fear of another impending disaster. A great deal of research was carried out to assess the threat and determine the epidemiology of the disease, resulting in rapid progress on the development of successful control measures. Nonetheless, certain aspects of oak wilt perplexed experts. For example, the origin of the pathogen was uncertain and it eventually became apparent that oak wilt was extant throughout much of the region originally considered to be free of the disease. This conclusion cast doubt on the opinion that the fungus was intensively spreading, as reported by many states. In addition, the sensitivity of the pathogen to high temperatures led to a failure to survey for the pathogen in the southern U.S. Although oak wilt distribution is limited relative to those of diseases caused by other exotic forest fungi, highly damaging epidemics do occur in parts of the disease range where aggressive, long-term suppression activities are justified. Based on our past experiences with this unusual disease, further attention on several fronts will be required if we are to be prepared for future threats from C. fagacearum.

Invasion, innovation, exploitation and coexistence: The birth and maturation of a pathosystem. T. Gordon. University of California, Davis, CA. Phytopathology 98:S187.

Pitch canker, caused by Gibberella circinata, was first recognized in 1946 as a disease of pines in the southeastern U.S. Since that time, pitch canker has become a global problem, affecting planted pines in Mexico, Chile, South Africa, Spain, South Korea and Japan. The extreme susceptibility of Pinus radiata, a species of great commercial importance, became apparent when pitch canker was identified in landscape plantings in California in 1986. The establishment of pitch canker in California was likely facilitated by dissemination of the pathogen on infested seed, infected but asymptomatic seedlings, logs cut from diseased trees and insects capable of vectoring the disease. Through various, inadvertent forms of human-intervention, these multiple modes of dispersal served to bring the pathogen in contact with populations of susceptible species in large areas of coastal California. Environmental requirements for infection appear to have limited expansion of the pitch canker infestation both to the north and into more inland locations. Another important limitation on development of pitch canker has been the manifestation of induced resistance, which appears to be largely responsible for recovery of many infected trees in areas where the disease has been present for many years. In stands that have been monitored since 1992 and where trees were severely diseased in 1996, few if any symptomatic trees could be found in 2002. Furthermore, individuals that were once heavily infected were subsequently shown to be resistant to pitch canker when directly challenged with the pathogen.

A century of responses to Cronartium ribicola: Have we made the right choices? P. Zambino. USDA Forest Service, Southern California Shared Service Area, San Bernardino, CA. Phytopathology 98:S187.

Cronartium ribicola, cause of white pine blister rust disease, was introduced to North America a century ago on infected pine seedlings. Minimizing risk to timber resources was historically a greater consideration than maintaining ecosystem function, prompting actions that allowed white pine species to decline drastically in many white pine-dependent ecosystems. High mortality in timber species prompted Ribes eradication programs, accelerated harvest, management for different tree species, and heavy reliance on resistance-screeing programs to provide seed for reforestation. Because of these measures, many western replacement forests have lower carbon sequestration and increased root disease and fire risk. Yet, white pine regeneration can occur and has occurred at many sites, while deployment of some resistance mechanisms identified by seedling screening can be limited by race-specific or climatespecific effectiveness or occurrence in a subset of pine populations. Discovery of Pedicularis and Castilleja alternate hosts is also modifying our concepts of disease risk for some ecosystems. Potential for natural selection for resistance in pine and alternate hosts, rust population differences, climate change, and rust adaptation to hosts and environment indicate that North American blister rust pathosystems will continue to evolve. Future management to stabilize ecosystems must take the risks and benefits of such dynamism into account.

Phytophthora - A day late and a dollar short. E. Hansen. Oregon State University, Corvallis, OR. Phytopathology 98:S187.

Our knowledge of Phytophthora, and our tools to manage it have advanced dramatically in the last 100 years. Today we have a much better understanding of the phylogeny, ecology, and pathogenesis of Phytophthora than we did then. Today we have selective media and selective fungicides; we have an elaborate regulatory apparatus. But if today's knowledge had been available 100 years ago would it have been used to slow the spread of P. cinnamomi in the SE U.S.? If a time machine had allowed Australians in 1950 to see the damage P. cinnamomi threatens to native forests and the incredibly diverse heathlands of Western Australia, would they have acted more quickly or with more resolve? How would today's tools have been deployed in 1920 when Phytophthora root rot began to kill ornamental Port Orford cedars on the west coast of the United States? Would it have been a different story in 1950 when the pathogen reached the native forests in SW Oregon? The record of the last decade certainly doesn't support any claim that our modern knowledge has changed our behavior significantly when it comes to slowing, let alone preventing, invasive Phytophthoras. The problem today is not so much lack of knowledge, but failure of will in a changing world. The pressures of population and globalization, the power of money, and accelerating environmental change keep us off balance and behind the curve.

\section{Epidemiology/Ecology/Environmental Biology}

\section{Epidemiology and Food Security: Historically Linked, Future of Promise}

The 'Continental Famine' of Europe, 1846/7; Causes and consequences. J. C. Zadoks. Emeritus Professor of Plant Pathology, Amsterdam, The Netherlands. Phytopathology 98:S187.
The 'Continental Famine' parallels the well-known 'Irish Famine', both in the late 1840s. Causes and consequences of the famine on the Continent were far more complex than in Ireland. Potato late blight was introduced into Europe in 1844 with tubers from the U.S.A. The potato late blight epidemic on the Continent began in the same year, exploded in 1845, and was severe again in 1846. In that year drought and heat damaged the Continental staple crops, rye 
first and foremost, but also potato. In addition a severe epidemic of yellow stripe rust hit the rye crops in several countries. The livelihood of tens of thousands people was destroyed by floods and severe hail storms in 1846 . Then the late blight came again. These agricultural mishaps were followed by the famine of 1846/7, an economic slum in 1847/8, and an epidemic of revolutions in 1848. Crop failure was one of the proximate causes of these revolutions but the ultimate cause was the yet unfulfilled promise of the Great French Revolution of 1789. The many new Constitutions of 1848 finally realized this promise and forever changed national politics in Continental Europe.

Linking plant diseases and their economic consequences in a global setting. P. G. Pardey (1) and S. Wood (2). (1) Intl. Science and Technology Practice and Policy Ctr (InSTePP), University of Minnesota, St. Paul, MN; (2) IFPRI, Washington. Phytopathology 98:S188.

As we transit to the 21 st century there are significant structural changes in the global demand for food, feed and fiber; shifts in the patterns of agricultural productivity generally and crop yields in particular; and a restructuring of the incentives for, investments in, and orientation and performance of agricultural research worldwide. All these changes have important implications for the funding and conduct of plant disease research aimed at maintaining the substantial gains in crop yields worldwide realized over the past several decades, and growing current yields over future decades. Making more effective use of scarce R\&D funds directed to crop disease research requires an understanding of these changing investment and institutional contexts. It also requires a more comprehensive understanding of the global yield, output and economic consequences of ameliorating the effects of crop diseases and pests. In this presentation we will describe and interpret some of the important structural changes affecting plant disease research. We will also layout new data and methods under development by the HarvestChoice project funded by the Gates Foundation to assess the economic effects of crop pests and diseases at spatial scales that are helpful for strategic crop research investment choices.

Plant disease epidemics and crop yield. L. V. Madden. Dept. of Plant Pathology, Ohio State University, Wooster, OH. Phytopathology 98:S188.

Epidemics continue to result in reductions in the quantity and quality of crop yield, both in developed and developing countries. Epidemiologists have made many contributions over the past half-century in quantifying the relationships between crop yield $(W)$ and attributes of epidemics, such as area under the disease progress curve (AUDPC) or disease at a single time $(Y)$.
However, the functional relationship between $W$ and AUDPC (or $Y$ ) is quite variable among studies, there typically is substantial variation within studies in $W$ at any given value of AUDPC (or $Y$ ), and there is uncertainty in crop-loss model parameters. Spatial heterogeneity of disease within fields is partly responsible for the yield heterogeneity and parameter uncertainty, as is the putative interactions of disease and yield with the micro- and macro-environment. Given the complex physiological processes involved in the production of harvestable biomass by crops, it is not surprising that more precise descriptions of the relationship between $W$ and population-level attributes of epidemics have not been achieved. Nevertheless, advances in relating $W$ to the integration of healthy (green) leaf area and radiation intercepted over time, and to the time of infection for systemic diseases, have led to improved precision in the prediction of yield, as well as new understandings of population biological processes. However, variability still remains high, suggesting that further improvements can be made in quantifying the risk of yield loss in relationship to disease development. Meta-analysis is one method that can be utilized to address the heterogeneity of crop loss results across experiments and surveys.

Strategic decisions for plant health management in a changing agriculture. S. Savary (1), P. Esker (2), and N. McRoberts (3). (1) IRRI, Los Baños, Philippines; (2) University of Wisconsin, Madison, WI; (3) Scottish Agricultural College, Edinburgh, UK. Phytopathology 98:S188.

Agriculture - its context, its resources, its scope - is changing. In some ways, one may consider that the rate of change is unprecedented. Agricultural change occurs at different scales, from the field, to entire eco-regions of the world, and these changes have consequences for plant health and plant health management. Effects include (i) reduced or increased disease epidemics, (ii) variation in crop vulnerability to diseases, and (iii) variation, and sometimes volatility, of resources for disease management. Strategic decisions are needed to anticipate the needs of future plant health management. In this paper, we distinguish three levels of decisions: D1, strategic-short term (made before a growing season); D2, tactical (made in the course of a growing season); and D3, strategic-long term (made within variable, sometimes large, horizons of time and space). Recent developments have focused on D1 and D2, with strong prospects for application and impact, and examples are discussed on, e.g., corn and grapevine. There is a need to develop a formal framework for D3, however. A starting point is the conventional (risk probability) $\times$ (risk magnitude), i.e., (epidemic risk) $\times$ (crop loss) approach, and is exemplified by the case of rice in Asia. Enhancing this approach with decision theory tools is discussed.

\section{Harnessing Emerging Molecular and Statistical Technologies for Analysis of Soilborne Pathosystems}

When to stop. Sampling challenges in estimating and comparing communities. M. Clayton. University of Wisconsin, Madison, WI. Phytopathology 98:S188.

Macro and micro ecologists have long struggled with the question of how to sample a community to determine species richness. An equally vexing problem is that of sampling communities with the goal of comparing them. Metagenomic methods provide increased sensitivity to sample unculturable community members, and at the same time expose more vividly the potential for inadequate sampling. We discuss newly developed methods for sampling, focusing specifically on community comparisons.

Coalescent approaches to determine the source of emerging, hostspecialized pathogen populations. P. Cerisini and B. McDonald. Plant
Pathology/Inst of Integrative Biology, Zurich, Switzerland. Phytopathology 98:S188.

Many plant pathogens form groups of closely related species that infect a broad array of plants. Traditional phylogenetic analyses based on sequencing rDNA-ITS and housekeeping genes often cannot determine lines of descent among different host-specialized populations. Population genetic approaches based on coalescent theory coupled with neutral genetic markers including microsatellites and DNA sequences provide powerful tools to differentiate between ancestral and decendent populations. Allele-specific PCR can be used to amplify both alleles in heterozygous diploid individuals and to determine whether host-specialized populations are present prior to first cultivation of a potentially susceptible crop. These tools can be useful for determining and implementing quarantine policies. A large-scale study conducted with Rhizoctonia solani AG1 IA infecting rice, maize, and soybeans will be presented as an example showing implementation of these tools and approaches.

\section{Impact of Plant Virus Epidemiology: Past, Present, and Future}

Plant virus epidemics. J. M. Thresh. Natural Resources Institute, University of Greenwich, Chatham Maritime, UK. Phytopathology 98:S188.

Many virus diseases have been described but relatively few become prevalent and cause serious losses. Inevitably, the diseases that cause damaging epidemics have received a disproportionate amount of attention from researchers and feature prominently in the Plant Pathology literature. This has long been apparent and examples will be given of epidemics that have occurred at various times and places in the 19th, 20th and 21st centuries. A notable feature of any such listing is the great diversity of epidemics. This is apparent in terms of the range of crops affected, the regions and agroecologies in which epidemics occur, the viruses responsible, and the vectors involved. It is also apparent that there is no single underlying cause of epidemics. Some are associated with particular weather conditions, or with a change in agronomic practices, or with the introduction of a new crop or particularly vulnerable cultivar. Other epidemics can be attributed to the introduction of a new virus or virus strain, or with a new vector species or biotype. Whatever the underlying cause epidemics can be regarded as notable and sometimes catastrophic events but ones that occur infrequently and are seldom sustained. On this view epidemics are seen as ecological perturbations of otherwise stable equilibria established between hosts and their pathogens. Furthermore, control measures can be viewed as a means of restoring the equilibrium and thereby safeguarding food security and crop production. The scope and 
validity of this concept merits further scrutiny and debate if plant virologists are to contribute effectively in attempts to increase the production of food and other crops. Moreover, they must do so using sustainable and environmentally sound procedures and despite the decrease in the rural labour force due to urbanization and the ravages of HIV/AIDS.

A case study: Significance, epidemiology, and management of hop viruses. S. J. PETHYBRIDGE (1), W. W. Turechek (2), and L. V. Madden (3). (1) Tasmanian Institute of Agricultural Research (TIAR), University of Tasmania, Cradle Coast Campus Burnie, Tasmania 7320, Australia; (2) USDA-ARS-USHRL Subtropical Plant Pathology, Fort Pierce, FL; (3) The Ohio State University/OARDC, Wooster, OH. Phytopathology 98:S189.

Hop latent carlavirus (HpLV), Hop mosaic carlavirus (HpMV), and Apple mosaic ilarvirus (ApMV) are viruses that have been shown to have deleterious effects on cone yield and brewing organic acids in several cultivars in Australian hop gardens, and pose a significant threat to the continued production of high yields. The means by which these viruses were spread within and between hop gardens was hypothesized from results of spatial, spatio-temporal, and association analyses, and later confirmed with additional experiments. Spatial analyses included ordinary runs, join-count, and radial correlation, and a stochastic spatio-temporal model was fitted to the data using Markov Chain Monte Carlo (MCMC) methods. Associations among these viruses were assessed using the Jaccard similarity index, Spearman's rank correlation coefficient, and spatial analysis by distance indices (SADIE). Combined results suggested spread of carlaviruses was predominantly within gardens, especially along rows. However, for HpMV epidemics in cultivar Agate, infections initiated from outside the garden, and immigrant viruliferous aphids were also important. Furthermore, the species of aphids that contributed to foci initiation within gardens were determined, the numbers of which were influenced by cultivar and location. A strong positive association between HpLV and HpMV was also found in all cultivars and at all locations, suggesting a common aphid vector species, despite the absence of the hop aphid, Phorodon humuli. ApMV incidence was also predominantly autocorrelated within gardens. Further experiments subsequently demonstrated transmission through pruning (simulated slashing for basal growth control), shoot contact, and root grafting. Recommendations for virus management from this research include the use of virus tested material for garden establishment and dessicant herbicides for basal growth control throughout the season.

Modeling yield loss based on time of virus detection: A geostatistical quadrat-based approach. F. W. Nutter, Jr. and E. Byamukama. Iowa State University, Ames, IA. Phytopathology 98:S189.

For many virus pathosystems, there is a strong relationship between time of symptom appearance (or virus detection) and yield, yet such relationships are rarely utilized to quantify yield losses caused by plant viruses. Yield loss models are essentially stimulus-response models that allow the use of regression to quantify the relationships between disease (or pathogen) incidence (x) and crop yield (y), as affected by environment, host (resistance) and virus strain (aggressiveness), interactions. These interactions include the duration (in time) that host and virus pathogen populations interact to affect yield and yield components. For example, time of tobacco etch virus symptom appearance (related to time of infection) in the aphid/bell/tobacco etch virus pepper pathosystem had an excellent quantitative relationship with reductions in yield ( $\mathrm{kg} / \mathrm{plant}$ ) and yield components (number of fruit/plant and fruit weight). In the bean pod mottle virus/soybean/bean leaf beetle pathosystem, it was the time that bean pod mottle virus was first detected (day of year) in 30$\mathrm{cm}$ soybean quadrats (by ELISA) that had the best relationship with reductions in soybean yield and yield components (e.g., the number of pods/plant and seed weight). For each 3-day period that BPMV detection (infection) within soybean quadrats could be delayed, soybean grain yield increased by $1 \%$. In units of actual yield, soybean yield increased by 1.0 bushel/acre for every 3 days that BPMV detection in quadrats could be delayed. In terms of yield components, soybean plants produced one additional pod for each 6-day delay that soybean quadrats were found to test positive for BPMV. Examples of sampling protocols, assessment protocols, and modeling approaches used to quantify the impact of time of plant virus infection, as measured by virus detection (symptoms appearance or by virus detection tools), on crop yield and yield components will be presented.

Modeling transmission: Disentangling the ecological trinity of plant host, virus and vector. M. Jeger. Imperial College London, Wye, Ashford, UK. Phytopathology 98:S189.

An understanding of transmission processes is the key requirement in modelling the dynamics of a plant virus epidemic. For most virus diseases this understanding depends upon a disentangling of the ecological trinity of plant host, virus and vector. Data on rates of acquisition and inoculation by vectors, periods of latency and infectiousness in both plant and vector, and aspects of vector performance and behaviour affecting transmission have been integrated in a basic epidemiological model enabling a comparison of the indirect transmission classes for insect-vectored virus diseases: non-persistent, semipersistent, persistent-circulative and persistent-propagative. Elaborations of this basic model have included: consequences of immigration and emigration in vector population dynamics; the interplay between infection in plant nurseries and plantation systems, where transmission is both horizontal (and indirect) through vectors and vertical (and direct) through vegetative cuttings; and linking within-plant virus dynamics to the population model to predict the emergence of damaging virus strains as a consequence of selection for some host resistance traits. In this paper the basic model will again be extended by including direct routes of transmission for persistent plant viruses in the vector population - horizontal transmission through venereal or other contact, and transovarial transmission to sexual progeny. These aspects have been welldescribed for arthropod vectors of vertebrate viruses and indeed for insect viruses, but are poorly understood for plant viruses. Analysis reveals a basic reproductive number that is the sum of three $R_{0}$ terms, one for each of the indirect horizontal (vector), direct horizontal (venereal) and direct vertical (transovarial) transmission routes. This analysis sets out what plant disease control must achieve when the direct routes of transmission are present. Also analysed is the often-raised question as to the evolutionary origin of some propagative plant viruses as insect viruses.

The emerging field of plant virus ecology. C. M. MALMSTROM (1), and U. Melcher (2). (1) Department of Biology and Center for Global Change and Earth Observations, Michigan State University, East Lansing, MI; (2) Oklahoma State University, Stillwater, OK. Phytopathology 98:S189.

Modern molecular approaches are increasingly revealing the extent of virus infection in wild plants. These findings provoke intriguing questions about the ecological roles of plant viruses in nature and the degree to which anthropogenic global change may alter virus influence. The emerging field of plant virus ecology seeks to address such questions by examining (i) the ecological roles of plant-associated viruses in managed and unmanaged ecosystems, and (ii) the reciprocal influence of ecosystem properties on the distribution and evolution of plant viruses. This field draws on the dual strengths of virology and ecology-two disciplines that historically experienced little intellectual exchange, except in the specific area of epidemiology, but which are now developing stronger collaborative connections. However, many ecologists remain unaware of the prevalence of virus infection in wild plants and many virologists remain unfamiliar with methods for examining the ecological consequences of such infections. To overcome these limitations, the NSF-sponsored international Plant Virus Ecology Network (PVEN) seeks to foster and accelerate research in plant virus ecology. Such research is expected to (a) uncover principles that control interactions among plants, viruses, vectors, and ecological factors in natural and managed ecosystems, (b) assess distributions and characteristics of established and emerging plant viruses globally, and (c) evaluate ecosystem consequences of plant virus activity and the influence of ecosystem properties on plant virus dynamics. Specific questions under investigation by the research community include: To what degree do plant viruses influence the structure and function of natural ecosystems? How is plant virus prevalence influenced by biodiversity and other ecosystem characteristics? Do native and exotic plants or other functional groups differ in infection rates? How does exchange between agricultural and natural systems influence virus evolution? Which factors have controlled geographic movement of viruses in the past and which may influence it in the future?

\section{Melhus Graduate Student Symposium: Forty-Five Years After Van Der Plank, New Visions for the Future of Plant Disease Epidemiology}

Quantification of temporal and spatial dynamics of bean pod mottle virus at different spatial scales. E. Byamukama, A. Robertson, and F. W. Nutter, Jr. Iowa State University, Ames, IA. Phytopathology 98:S189.
Bean pod mottle virus (BPMV) is the most prevalent virus infecting soybean (Glycine max) in the U.S., however, the temporal and spatial changes in BPMV at the field and county scales have not been reported. To quantify the temporal and spatial spread of BPMV, a quadrat-based method was developed. In 2006 and 2007, 30-cm-long quadrats were established within field plots (150 quadrats per plot). Quadrats were sampled by selecting the youngest, fully-expanded leaflet from each of four plants within a quadrat beginning 25 days after planting and continued at 8-11 day intervals until 
crop senescence. Leaf sap was extracted from each 4-leaflet (bulked) sample (from each quadrat), and tested for presence of the BPMV by ELISA. Quadrat position (plot, row, and quadrat number), and the date of sampling that each quadrat first tested positive for BPMV were recorded and mapped. The rate of BPMV infection in 2006 ranged from 0.09 to 0.17 logits/day, indicating that BPMV incidence was doubling every 4.1 to 7.7 days. Doubling times in 2007 were slower, ranging from 17.3 to 34.7 days. Spatial analyses using both ordinary runs and black and white joins revealed clustering of BPMV-infected quadrats occurred throughout the growing season. A three-year statewide disease survey (2005-2007) was done in Iowa to quantity both field and county level BPMV prevalence and incidence by systematically selecting 30 plants/soybean field (8-20 fields/county) and testing them for BPMV by ELISA. The GPS coordinates for each soybean field sampled were also recorded. Field and county-level BPMV prevalence and incidence maps were generated using ArcGIS. County-level prevalence of BPMV was 39/96 counties in 2005 (40.6\%), 90/99 counties $(90.1 \%$ ) in 2006, and 74/99 counties (74.7\%) in 2007. The incidence of BPMV within counties ranged from 0 to $100 \%$. At the county level, there was significant spatial dependence for BPMV incidence based on Moran's I analysis, indicating that counties with high BPMV incidence tended to be neighbored by counties that also had high BPMV incidence, and counties with low BPMV incidence tended to be neighbored by counties with low BPMV incidence. The significance of temporal and spatial dynamics of BPMV and distribution of BPMV in Iowa in sampling, management and risk of BPMV will be discussed.

Role of hairy nightshade Solanum sarrachoides (Sendtner) in the transmission of Potato virus Y (PVY) strains by aphids and study of different PVY strains reaction on Solanum tuberosum (Linnaeus). F. A. Cervantes and J. M. Alvarez. University of Idaho, Aberdeen, ID. Phytopathology 98:S190.

Potato virus Y (Potyvirus: Potyviridae) (PVY), the most economically important virus affecting the potato industry in the United States, is vectored by several potato colonizing and non colonizing aphid species in a non persistent manner. Transmission and spread of the virus depends among other factors on the transmission efficiency of the aphid vector species, the amount of initial inoculum, and the virus strain. Thus, aphid control by itself does not prevent spread of PVY unless measures are also taken to keep virus-source plants at a minimum. We examined the role of $S$. sarrachoides as a source of virus inoculum in the transmission of PVY by three aphid vectors Myzus persicae (Sulzer), Macrosiphum euphorbiae (Thomas), and Rhopalosiphum padi (L) (Homoptera: Aphididae) under field and laboratory conditions. Under laboratory conditions transmission of PVYO and PVYNTN by M. persicae and $M$. euphorbiae was higher in hairy nightshade plants than in potato plants. Transmission of PVYO and PVYNTN by $R$. padi was very low with no differences between treatments. Under field conditions hairy nightshade increases the percentage of PVYO transmission by the three aphid species. The pathosystem complexity is increased by the high genetic variability of PVY. We examined the interactions that take place between M. persicae and three PVY strains in hairy nightshade and potato. We observed that PVYNTN and PVYN:O (necrotic strains) are more readily transmitted by $M$. persicae than PVYO (non necrotic strain). In the case of hairy nightshade titer levels were positively correlated with percentage of infection. Necrotic strains reached higher titers in both hairy nightshade and potato (three potato cultivars) than the $\mathrm{O}$ strain. These results help understand the relations among the aphid vectors, the virus and the virus inoculum sources in order to develop alternate, inexpensive and environmentally friendly vector and virus-disease management tools.

New perspectives on the epidemiology of citrus stubborn disease in California orchards. A. F. S. Mello (1), R. K. Yokomi (2), U. Melcher (1), J. C. Chen (2), E. Civerolo (2), A. Wayadande (1), and J. Fletcher (1). (1) Oklahoma State University, Stillwater, OK; (2) USDA, ARS, Parlier, CA. Phytopathology 98:S190.

Although citrus stubborn disease (CSD), caused by the phloem resident mollicute Spiroplasma citri, is a significant threat to California citrus industry our knowledge of its epidemiology is mostly anecdotal. We optimized multiple pathogen-detection protocols, measured disease incidence in two plots of commercial California groves, assessed pathogen impact on fruit quality and yield and evaluated genetic diversity among $S$. citri strains. Fruit columellas and receptacles were more suitable than leaves or bark for bacterial cultivation. Using cultivation and $S$. citri-specific PCR for detection, the incidence of CSD in two sampled orchards, respectively, ranged from 46 to $85 \%$ and 1 to $4 \%$, depending on the sampling technique. Yield and quality of fruits produced by trees that were mildly or severely CSD-symptomatic were compared to those of S. citri-free trees in one California orchard in 2006 and 2007. These infected trees had 30\% lower yield and reduced fruit quality than $S$. citri-free trees. Using RAPD markers to compare $35 \mathrm{~S}$. citri strains isolated 20 years ago from the U.S. and Mediterranean region with 34 strains recently collected from California, significant genetic diversity was identified but was not correlated with the time of collection or location. However, some host associations were observed. Our findings suggest that CSD incidence in the commercial groves evaluated could be as high as $84.8 \%$ and its impact on yield and fruit quality are significant.

Development of an advisory system for grapevine powdery mildew in eastern North America: A reassessment of epidemic progress. M. Moyer, D. M. Gadoury, W. F. Wilcox, and R. C. Seem. Cornell University, N.Y. State Agric. Exp. Stn., Geneva, NY. Phytopathology 98:S190.

Analysis of historical data on weather and severity of fruit infection in NY indicated that year-to-year variation in severity of fruit infection was not directly related to annual variations in temperature or RH through their known effects upon conidial germination, colony expansion, or latent period. Although severity of fruit infection varied from 0.02 to $61 \%$ among years, these environmental factors generally remained in the optimal range for the pathogen, with only slight year-to-year variations during the brief period that fruit were susceptible to infection. Vineyard experiments in NY and Australia indicated that colony growth was slower and sparser than would be expected from previous lab studies. Additional experiments indicated that transient exposure to temperatures near $4^{\circ} \mathrm{C}$ for a few hours had a debilitating effect on mildew colonies and produced growth similar to that observed on ontogenically-resistant tissues: slow and sparse with epidermal necrosis. Additional studies on seasonal release of ascospores from overwintering cleistothecia indicated that a large proportion of inoculum was often released prior to local grapevine budbreak at multiple sites in the eastern U.S. These findings may represent key elements in forecasting potential severity of fruit infection in cool climates such as New York.

\section{Plant-Associated Bacteria in Their Natural Habitat}

A century of phytobacteriology: Old and new questions about bacterial wilt. C. Allen. Department of Plant Pathology, University of Wisconsin, Madison, WI. Phytopathology 98:S190.

In 1896 Erwin F. Smith used Koch's Postulates to show that Bacillus solanacearum causes bacterial wilt disease of tomato and potato. In the next few decades, researchers focused on understanding how the pathogen survives, infects, and induces wilting on such a wide range of hosts. Early 20th-century plant pathologists asked how B. solanacearum survived without host plants; did it latently infect weeds or native plants, or multiply in water? How did the bacterium form the latent infections that threatened vegetatively propagated hosts like potato and banana? What explained the extreme heterogenity of the species, and its rapid loss of virulence in culture? Finally, what was the mechanism of wilting - did the bacterium produce a toxin injurious to the plant or simply obstruct the xylem vessels? Although we have partial answers to some of these questions, most, such as the mechanisms underlying variability, wilting and latent infections, are still actively studied. The epidemiology of Ralstonia solanacearum (as it is now known) remains poorly understood, and most wilt disease control methods would be familiar to E. F. Smith. Genomic-level analyses combined with in planta imaging and gene expression monitoring are allowing us to address old questions in a systematic, integrated way. Using these tools to study the pathogen in natural hosts, we hope to better understand the environment this bacterium experiences inside its host plants, and the tools it uses to succeed there.

Pseudomonas syringae: Partner and actor in the natural cycle of water. C. E. Morris. INRA UR 407 Pathologie Végétale, Montfavet, France. Phytopathology 98:S190.

Pseudomonas syringae is an archetype among the plant pathogenic bacteria. Its biology, ecology and genetics have been extensively studied, but almost exclusively in relationship with plants and agricultural habitats. The ensemble of its known behaviors led us to postulate that it is also present in non agricultural habitats associated with water, leading us to discover its abundant in rain, snow, alpine streams and lakes, epilithic biofilms and wild plants - in addition to the previously reported presence in aerosols and clouds. Most strains are pathogenic (induce HR on tobacco, are virulent on several plant species) and produce syringomycin-like toxins, but up to $20 \%$, depending on substrate, are non pathogenic. Phylogenetic analyses based on four housekeeping genes confirmed identity as $P$. syringae. Moreover, strains belonging to the same clonal lineage were isolated from snow, irrigation water, and a diseased crop plant illustrating its long distance dissemination. 
Furthermore, the different substrates harboring $P$. syringae seem to modify the structure of the associated populations. We propose a comprehensive life cycle for P. syringae - in agricultural and non agricultural habitats - driven by the environmental cycle of water. This cycle opens the opportunity to evaluate the importance of non agricultural habitats in the evolution of a plant pathogen and the emergence of virulence. The ice nucleation activity of all strains from snow, unlike from other substrates, suggests that $P$. syringae plays an active role in the water cycle as an ice nucleus in clouds thereby facilitating its dissemination.

Streptomyces from the dark side: Mechanisms and emergence of pathogenicity. R. LORIA, D. Bignell, J. Huguet, E. Johnson, M. Joshi, S. Moll, and R. Seipke. Cornell University, Ithaca, NY. Phytopathology 98:S191.

Among the multitude of soil-inhabiting, saprophytic Streptomyces species are a growing number of plant pathogens that cause economically important diseases, including potato scab. Streptomyces scabies is the dominant pathogenic species worldwide and, along with $S$. turgidiscabies and $S$. acidiscabies, has been the subject of ecological analysis over decades. Recently, molecular genetic and genomic analysis of these pathogens has provided explanations for the emergence of new pathogenic species and other problematic aspects of disease control. Emergence of locally adapted potato scab pathogens can now be attributed to mobilization of an integrative, conjugative element (ICE) carrying many pathogenicity genes. The newly emerged pathogen S. turgidiscabies Car8 carries a $660 \mathrm{~kb}$ version of the ICE encoding many virulence loci, including the genes encoding the thaxtomin biosynthetic pathway. A nitric oxide (NO) synthase provides NO for nitration of the dipeptide toxin and for release at the plant-pathogen interface. Thaxtomin facilitates penetration by inhibiting cellulose synthesis in developing plant cells. Toxin activity is consistent a conserved plant cell target and with the lack of host and tissue specificity of scab pathogens. Regulation of thaxtomin biosynthesis via a cellobiose-binding AraC/XylS family regulator supports a model by which thaxtomin biosynthesis increases in the presence of expanding plant tissue, which is the site of infection on potato and other hosts. Ongoing comparative and functional genomic analysis is providing additional insight on the mechanisms by which these economically important and fascinating pathogens manipulate plant cells and continue to evolve in agricultural systems.

Life on the leaf: How bacteria survive during vegetable production. $\mathrm{H}$. W. Lange, M. A. B. Herman, H. C. Hoch, and C. D. SMART. Department of Plant Pathology and Plant-Microbe Biology, Cornell University, Geneva, NY. Phytopathology 98:S191.

Bacterial plant pathogens of vegetable crops must withstand a multitude of environmental pressures during greenhouse transplant production as well as in the field. In addition to weather conditions that could modify pathogen growth and survival, bacterial pathogens also have to tolerate plant defense responses and disease control products such as copper, antibiotics and bacteriophage. We are using Xanthomonas campestris pv. campestris (Xcc) and Pseudomonas syringae pv. tomato (Pst) as model systems for studying bacterial survival and spread. Using real-time PCR we have followed the movement of Xcc through greenhouse transplant production under various disease management strategies. Additionally, we have followed the pathogen population of Pst during an epidemic in the field. While all control strategies slowed pathogen growth compared to the untreated control, the treatment containing a combination of two plant activators (Acibenzolar-S-methyl and a Bacillus spp. plant growth-promoting rhizobacterium) had significantly fewer bacteria than other treatments. The correlation between pathogen growth and the induction of plant defense responses, including systemic acquired resistance, based on marker gene expression will also be discussed.

Pseudomonas gene expression during growth in the rhizosphere. E. T. GONZALEZ (1), W. P. Wechter (2), and D. A. Kluepfel (1). (1) USDA ARS Crops Pathology and Genetics Research Unit, Davis, CA; (2) USDA ARS Charleston Vegetable Laboratory, Charleston, SC. Phytopathology 98:S191.

The plant rhizosphere is a nutrient rich oasis for soil dwelling microbes, both benevolent and pathogenic. Perhaps one of the best-studied groups of bacteria that live in this niche are the fluorescent pseudomonads. This due to the variety of traits they display, such as secondary metabolite production and plant disease protection. To gain a comprehensive understanding of bacterial genes that mediate rhizosphere colonization, we evaluated the expression of $P$. putida KT2440 genes during growth in the rhizosphere of Arabidopsis thaliana using microarrays; gene expression of all 5350 open reading frames of $P$. putida KT2440 was evaluated 48 and 120 hours post inoculation. A total of $1.8 \%$ and $5.5 \%$ of the P. putida KT2440 genome was modulated 48 and 120 hours post inoculation, respectively. Genes annotated as hypothetical proteins with unknown function represented the majority of genes whose expression is modulated in response to growth in the rhizosphere. These genes made up $43.8 \%$ and $41.6 \%$ of the total number of modulated genes at 48 and 120 hours post inoculation, respectively. However, genes with previously identified roles in root colonization also were induced at both time points. This group includes genes involved in chemotaxis, motility, iron sequestration, and amino acid transport and biosynthesis. Thirty-two genes were induced at both 48 and 120 hours post inoculation; therefore, we hypothesize that genes in this category are important in rhizosphere colonization. To evaluate the role of these genes in general root colonization and seed adhesion, several $P$. putida and $P$. aeruginosa mutants were tested. Results from this study, as well as two other microarray-based studies of Pseudomonas gene expression, will be discussed.

Acid, metal, and punk bacteria: Adaptation of Pseudomonas syringae to growth in plants. G. M. PRESTON (1), A. Rico (1), H. Fones (1), A. Mithani (2), R. Jones (1), J. Hein (2), and A. Smith (1). (1) Department of Plant Sciences, University of Oxford, Oxford, United Kingdom; (2) Department of Statistics, University of Oxford, Oxford, United Kingdom. Phytopathology 98:S191.

The bacterial pathogen Pseudomonas syringae colonizes foliar surfaces and the intercellular spaces between plant cells, where it assimilates nutrients present in apoplastic fluid and in plant exudates. Endophytic growth of $P$. syringae depends on the activity of a type III protein secretion system, which acts in conjunction with low molecular weight toxins and phytohormones to suppress plant defences responses and alter plant physiology. However, relatively little is known regarding the physiological and metabolic adaptations that allow $P$. syringae to grow in plant tissues. Analyses of apoplast composition and nutrient assimilation show that $P$. syringae is well adapted for growth in the apoplast of susceptible host plants. Experimental analyses of nutrient assimilation by $P$. syringae are supported by bioinformatic predictions of metabolic pathways, which show that $P$. syringae contains pathways needed to assimilate metabolites that are abundant in the plant apoplast. Analyses of apoplast composition and bacterial growth in apoplast extracts can also be used to investigate the role of anti-microbial chemicals in limiting $P$. syringae growth in planta. For example, analyses of metal concentrations and bacterial growth in apoplast extracts from the metalhyperaccumulating plant Thlaspi caerulescens show that metal concentrations in the leaf apoplast reach levels high enough to account for the high resistance of metal-treated plants to infection by $P$. syringae.

\section{Potential Impacts of Climate Change on Diseases in Natural Ecosystems: Using History to Predict the Future}

Climate change and plant disease in tallgrass prairie. K. A. Garrett. Kansas State University, Manhattan, KS. Phytopathology 98:S191.

Climate change predictions for the tallgrass prairie regions of the Great Plains include shifts to fewer, larger precipitation events, potentially resulting in longer periods of drought stress. In experiments with the dominant tallgrass prairie grass, big bluestem, drought stress led to increased rust severity upon recovery from drought, associated with reduced expression of some genes associated with disease resistance and dampened phytohormone responses to rust. Our research group evaluated visually-distinct foliar symptoms in synoptic samples of over twenty of the most common tallgrass prairie species in a long-term field study. We analyzed the response of disease to three important sources of variation in tallgrass prairie: position in upland vs. lowland locations, time between burning, and the presence or absence of native grazers. The highest disease incidence was observed for rust of big bluestem and rusts were the most common foliar diseases observed for all plant species studied. The most important abiotic predictor of disease incidence was topographic position, with higher infection levels in lowland positions that are generally wetter and more sheltered. Shifts in land use may also play a role in shaping future disease pressure, since pathogens are shared between tallgrass prairie and the grass-based agricultural systems of the region.

Genetic responses to climate change: Comparisons between quantitative and molecular genetics in western white pine. B. Richardson, G. Rehfeldt, and M.-S. Kim. USDA Forest Service-RMRS, Moscow, ID. Phytopathology 98:S191.

A rapidly changing climate will have a substantial influence on plant disease. A critical component of forecasting future disease impacts in natural 
ecosystem is predicting host distributions and climatically adapted populations. Here we examine the host and climate interactions from a species and population level of western white pine (Pinus monticola). First, bioclimate modeling is used to predict the species distribution using a climate surface. Climate surfaces are developed from weather station data and updated using general circulation models (GCMs) for future climates. Second, genecological models based on quantitative traits and molecular markers are used to elucidate climatically adapted populations. The bioclimate and genecological models are mapped based on contemporary or future climate surfaces. The results from this approach are discussed including a comparison of molecular and quantitative genecological models, predicted species and population movements based on future GCM scenarios and identifying populations or regions potentially at risk to expiration due to maladaption and disease.

Increased severity of alder canker expected with climate change in Alaska: Can hosts adjust physiology to compensate for disease? J. RohrsRichey. University of Alaska, Fairbanks, AK. Phytopathology 98:S192.

Within the last 50 years, Alaska has experienced a climate-related shift in a nitrogen-fixing, keystone species. Alders (Alnus spp.) are migrating into the tundra and expanding into Interior river drainages. Recently, high incidence and severity of an alder canker disease (associated with fungal pathogen Valsa melanodiscus (anamorph = Cytospora umbrina) has been documented in Alaska. The disease causes vascular tissue death, long, girdling cankers, and frequent stem mortality of thin leaf alder (A. tenuifolia) and green alder $(A$. crispa). Changing climate is expected to facilitate disease development, as host plants are likely to experience temperature-induced drought stress. Combined effects of canker disease and water stress on A. crispa physiology were investigated through greenhouse inoculation experiments at the University of Alaska. The goal was to measure the affects of canker development on water transport, photosynthesis (PS), and stomatal conductance $\left(g_{\mathrm{s}}\right)$. Leaves on diseased stems did not attain the high PS rate and high light saturation of healthy stems. Leaves from well-watered, diseased stems, however, had PS rates similar to those of healthy stems over a lower range of $g_{\mathrm{s}}$ values $\left(0.04\right.$ to $0.08 \mathrm{~mol} \mathrm{H}_{2} \mathrm{O} \mathrm{m}^{-2} \mathrm{~s}^{-1}$ compared to healthy stems 0.08 to $0.10 \mathrm{~mol} \mathrm{H}_{2} \mathrm{O} \mathrm{m}^{-2} \mathrm{~s}^{-1}$ ). Conservative $g_{\mathrm{s}}$ values were also reflected in high water use efficiency for leaves on diseased, water-stressed stems. These preliminary results indicate that regulation of $g_{s}$ can compensate for physiological limitations of disease. Stomatal regulation relies on hydraulic and chemical signals, and our results suggest that water availability may determine the extent to which this mechanism can operate under stressful climate conditions.

Toward determining the influence of climate change on Armillaria root disease in western North America. M.-S. Kim, N. B. Klopfenstein, B. A. Richardson, J. W. Hanna, and G. I. McDonald. USDA Forest Service-RMRS, Moscow, ID. Phytopathology 98:S192.

Armillaria root disease has an extremely wide distribution in forests worldwide, with extensive occurrence in northwestern North America. Climate factors are critical in determining the distribution of Armillaria spp. However, the precise distribution of accurately identified, root-disease pathogens must be documented, so that areas with suitable climate for supporting Armillaria spp. can be predicted for the western U.S.A. and elsewhere. After climate variables that influence present Armillaria spp. distribution are determined, then models that predict future climate can be used to predict areas where Armillaria spp. may occur under future climate scenarios. In addition, suitable climate space for many tree species is expected to change dramatically during this century. Some insights into Armillaria root disease can be gained by comparing predicted potential distributions of Armillaria spp. with those of susceptible tree species. Furthermore, it is likely that a majority of trees may become maladapted during climate change, and Armillaria root disease is typically more severe in trees that are maladapted to climate-induced stress. Thus, it seems likely that climate change will exacerbate damage from Armillaria root disease, and may further predispose trees to beetle attack. Approaches to predict potential influences of climate change on Armillaria root disease will be discussed.

\section{Molecular/Cellular Plant Microbe Interactions}

\section{Bacterial Type III Secretion Systems: From Enigmatic avr and $h r p$ Genes to Type III Effector-Mediated Suppression of Plant Immunity}

From the discovery of avirulence proteins to effector-dependent inhibition of plant signal transduction. B. Staskawicz. University of California, Berkeley, CA. Phytopathology 98:S192.

It has now well established that all classes of pathogens are able to deliver effector proteins directly to host plants often via specialized infection structures. Pathogen effector proteins are involved with the suppression or modulation of plant innate immunity and fundamentally control plant pathogenesis. Interestingly, the same proteins that modulate pathogen virulence are also involved in triggering genotype-specific plant disease resistance. In this presentation, I will highlight the original approaches that led to the discovery of pathogen effectors and how this information has shaped our current understanding of the "dual" role of effectors in both plant pathogenesis and the activation of disease resistance signalling pathways. Furthermore, I will provide recent data from my laboratory in our attempts to employ pathogen effector proteins as molecular probes to identify host targets controlling plant innate immunity. Finally, I will explore genomic strategies to ascertain the repertoire of effector proteins that are present in field strains of an important bacterial pathogen and how this information may used to molecularly breed for durable resistance.

Discovery of the Hrp system, a door to the inner world of bacterial virulence. A. Collmer. Cornell University, Ithaca, NY. Phytopathology 98:S192.

Type III secretion systems (T3SSs) provide a portal for the delivery of virulence effector proteins from bacteria into eukaryotic host cells. The T3SS of plant pathogens is encoded by hrp genes, which were discovered in Pseudomonas syringae in the 1980's and so-named because mutants failed to elicit the defense-associated hypersensitive response in resistant plants and were not pathogenic in susceptible plants. A series of subsequent discoveries revealed that hrp genes are carried in horizontally acquired clusters in many bacterial pathogens, encode a protein secretion system with core components shared with flagellar and animal pathogen T3SSs, and inject into plant cells Avr/Hop/effector proteins whose primary role is to suppress plant defenses but whose detection by $\mathrm{R}$ gene-mediated surveillance can limit host range and determine host specificity. Cloned, complete hrp gene clusters that enable nonpathogens to deliver single effectors have provided important tools for exploring the functions of effectors and also components of the T3SS machinery, approximately a third of which also travel the pathway. Many important questions remain unanswered. How is the Hrp system regulated as bacteria interact with plants? How is the Hrp T3SS adapted for delivery of effectors across the wall and plasma membrane of plant cells? Is there a hierarchy in the passage of various proteins through the Hrp pathway, and how is this controlled? Progress and new questions will be discussed.

Learning about bacterial suppression of PAMP-triggered innate immunity from studying type III effectors AvrPto, HopM1, and AvrE1. S. Y. He. Michigan State University, East Lansing, MI. Phytopathology 98:S192.

Suppression of host innate immunity appears to be an important aspect of Pseudomonas syringae infection of susceptible plants. An increasing number of effector proteins secreted through the P. syringae type III secretion system (TTSS) have been implicated in this process. This talk is aimed at giving an overview of experiments that led to the identification of three TTSS effectors (AvrPto, HopM1, and AvrE) from Pseudomonas syringae pv. tomato as suppressors of plant innate immunity. In particular, HopM1 and AvrE make a large contribution to $P$. syringae virulence and appear to be functionally redundant. HopM1 was found to interact with and destabilize several Arabidopsis host proteins (AtMINs). AtMIN7 is an ARF family of guanine nucleotide exchange factors (GEFs) predicted to be involved in vesicle traffic. Compared with wild-type plants, atmin7 knockout plants show enhanced susceptibility to the $P$. syringae pv. tomato DC3000 deltaCEL mutant in which hopM1 and avrE have been deleted. These results suggest an important role of vesicle traffic in plant innate immunity. The involvement of other AtMIN proteins in HopM1 function is under investigation. The host targets of AvrE remain unknown, but AvrE contains two WXXXE motifs present in several mammalian pathogen effectors that mimic activated small $\mathrm{G}$ proteins. Interestingly, mutations in these motifs abolish AvrE virulence activity, raising the intriguing possibility that AvrE functions through affecting host small G-protein-mediated processes. Identification of host targets of AvrE may be particularly important, as AvrE orthologues in several bacterial pathogens are essential pathogenicity factors. Finally, how to block the virulence action of HopM1 and AvrE will be discussed as a possible strategy for bacterial disease control. 
The molecular basis of plant immunity suppression by the Pseudomonas syringae type III effector HopU1. J. Alfano. University of Nebraska, Lincoln, NE. Phytopathology 98:S193.

The bacterial plant pathogen Pseudomonas syringae is dependent on the type III protein secretion system (T3SS) and effector proteins it injects into host cells to cause disease. Recently, many $P$. syringae effectors have been shown to suppress plant innate immune responses. However, the majority of their enzymatic activities and their plant substrates remain unknown. We purified one of the $P$. syringae effector HopU1 using the His-tag and demonstrated that it was a mono-ADP-ribosyltransferase (ADP-RT) active on an artificial substrate and proteins in Arabidopsis thaliana and tobacco. Using ADP-RT assays coupled with mass spectrometry we identified the major HopU1 substrates in A. thaliana to be several RNA-binding proteins that possess RNA-recognition motifs (RRMs), which are generally required for binding RNA. Genetic analyses of one of the target, a glycine-rich RNA-binding protein AtGRP7, revealed that T-DNA knock-out lines were more susceptible than wild type plants to $P$. syringae infection and showed reduced innate immune responses. The ADP-ribosylation of AtGRP7 by HopU1 required two arginine residues within the RRM of AtGRP7, R47 and R49. We found that R49 was ADP-ribosylated by HopU1 and that this modification significantly decreased AtGRP7's ability to bind RNA. Modeling of the RRM domain of AtGRP7 indicated that R49 would likely make contact with RNA. Thus, the pathogen has evolved to target an amino acid residue within an RNA-binding protein to disrupt its ability to bind RNA. Our results suggest a novel strategy employed by a bacterial pathogen where the ADP-ribosylation of plant RNAbinding proteins results in the posttranscriptional inhibition of host innate immunity by affecting RNA metabolism.

Impact of Xanthomonas AvrBsT effector action on signaling and immunity in Arabidopsis. M. B. Mudgett. Stanford University, Stanford, CA. Phytopathology 98:S193.
We use the Pseudomonas-Arabidopsis model pathosystem to study the impact of AvrBsT, a type III effector protein from Xanthomonas campestris pathovar vesicatoria, on host signaling and immunity during infection. We discovered that AvrBsT alters host physiology in sober1 mutant plants resulting in the activation of salicylic acid-dependent and independent defense responses. SOBER1 (suppressor of AvrBsT-elicited resistance 1) is a carboxylesterase predicted to work on lysophospholipid or acylated protein substrates. The function of AvrBsT is unknown; however, the Yersinia homolog YopJ encodes an acyltransferase that inhibits kinase signaling in animals. In this work, we have isolated AvrBsT and SOBER1 protein interactors to identify the signaling pathways that are directly affected by AvrBsT. In addition, we have characterized the temporal and organ-specific expression of SOBER 1 to elucidate how SOBER1 suppresses AvrBsT-triggered cellular perturbations. I will present our new insights regarding AvrBsT-SOBER1 signaling in Arabidopsis and how it relates to the pathology observed in the natural Xanthomonas-tomato interaction.

Bacterial effector activation: Investigating the significance of cyclophilininduced protein folding. G. Coaker. University of California, Davis, CA. Phytopathology 98:S193.

Gram-negative bacterial pathogens use the Type III Secretion System (TTSS) to deliver bacterial effector proteins required for pathogenesis into host cells. Due to size constrains of the TTSS, effectors are delivered into host cells as unfolded proteins, act as eukaryotic enzymes and can usurp host protein folding catalysts. We have identified cyclophilin, a chaperone and folding catalyst, as the eukaryotic activator of the Pseudomonas syringae effector AvrRpt2. Bioinformatics analyses have identified cyclophilin binding sites in many effectors from diverse plant pathogens. Thus, cyclophilin may act as a molecular switch, controlling effector protein folding and activation inside host cells. Recent data from my laboratory illustrating cyclophilin activation of additional effectors will also be presented.

\section{Fungal Genomics Enters the Post-Genome Era}

The genome of Blumeria graminis: A systems approach to the biology of powdery mildews. P. D. Spanu. Department of Life Sciences, Imperial College London, London, UK. Phytopathology 98:S193.

We have sequenced the genome of Blumeria graminis f. sp. hordei, (DH14). Projections of genome size estimate a value of around $120 \mathrm{Mb}$, much higher than expected due to large amounts ( $>60 \%$ ) of repetitive DNA mostly unique to Blumeria. Current genome coverage $(\sim 4 \mathrm{X})$ is being extended by highthroughput sequencing, with particular attention to the non repetitive "genespace". Genome assembly is congruent with existing published maps of genetic markers. cDNA libraries from conidia, germlings isolated from infected barley (20hpi, 3dpi and 6dpi), cleistothecia and infected barley epidermis have also been sequenced. This is primarily used to train Blumeriaspecific gene finding programs and to contribute to the annotation of the genome. Over $93 \%$ of these ESTs can be mapped to the current genome. The ESTs identify 3622 unigenes. All this data is publicly available through the website www.blugen.org. All clones are also available for anyone requesting them through this website. A comparative analysis of transcriptome dynamics identified clusters of genes that are co-ordinately expressed or mis-expressed during germination and early development on host, non-host and artificial surfaces, respectively. There are no significant and detectable differences in gene expression on the host barley compared to the non-host wheat prior to penetration but large differences exist when these are compared to growth on artificial surfaces which induce aberrant development. Phylogenetic footprint analysis of the 5'DNA upstream of these genes identifies putative promoters and regulatory elements controlling their expression. We have initiated a systematic analysis of the Blumeria proteome which we anticipate will reveal novel insights into secretion, pathogenesis and effector biology of these obligate biotrophic pathogens.

A killer sequence: Genomics of the necrotrophic fungal pathogen Sclerotinia sclerotiorum. M. Dickman (1), C. Cuomo, L. Kohn, and J. Rollins. (1) Institute for Plant Genomics and Biotechnology, Department of
Plant Pathology and Microbiology, Texas A\&M University, College Station, TX. Phytopathology 98:S193.

Sclerotinia sclerotiorum (Lib.) de Bary is among the world's most successful fungal plant pathogens infecting nearly all dicotyledonous plant species. Despite considerable effort, resistant germplasm is still lacking in economically important crops. As a standard for necrotrophic pathogenesis, it is also a good model for studying the development of sclerotia, sexual fruiting and host-pathogen compatibility via fungal-induced plant cell death. It is also central to a group of Ascomycetes with poorly known evolutionary relationships. The Sclerotinia sclerotiorum genome-sequencing project has produced an $8 \mathrm{X}$ sequence assembly comprised of 36 scaffolds totaling $38 \mathrm{Mb}$ (http://www. broad.mit.edu/annotation/genome/sclerotinia_sclerotiorum/Home.html). This assembly was validated and mapped to 16 chromosomes using an optical map produced by OpGen. More than 70,000 EST sequences have also been generated representing six different development stages or growth conditions. With this sequence data, an automatic annotation process identified and partially annotated 14,522 predicted genes. A total of $72 \%$ of these proteins have a Blastp hit (1e-5) to a fungal protein database. This wealth of sequence data has opened opportunities for comprehensive transcriptomic and comparative genomic studies. From the genome sequence of 1980 and an Australian isolate, $500 \mathrm{SNPs}$ distributed on all linkage groups have been developed. Analysis has provided evidence for inter-and intra-chromosomal recombination. Agilent microarrays have been designed containing 38,637 unique Sclerotinia-derived 60-mer oligonucleotide sequence elements. The closely related species Botrytis cinerea, has recently been sequenced in Europe and we have partnered with the Botrytis genome-sequencing consortium. These genomes share 10,039 proteins with an average of $76 \%$ similarity. Joint manual annotation of the Sclerotinia and Botrytis genomes has been initiated and has prompted comparative studies focusing on genome evolution, necrotrophic pathogenicity and mating-type evolution. Comparative genome studies with closely related species provide excellent opportunities for understanding the evolutionary and genetic basis of shared and unique traits, genetic variability, population biology and basic principles of pathogenesis.

\section{Plant Virology: Impact on Science and Society}

Plant virology in the 20th century. B. D. Harrison. Scottish Crop Research Institute, Invergowrie, Dundee DD2 5DA, UK. Phytopathology 98:S193.

The development of plant virology as a science is, almost totally, a 20thcentury phenomenon. Early papers on plant viruses emphasize ultra- filterability and report transmission by leafhopper and aphid vectors, and through soil or seed. Successive advances were largely driven by access to new techniques. For example, biochemical approaches, and local-lesion and serological assays, led to purification and crystallization of virus particles, and their identification as nucleoproteins; electron microscopy and X-ray crystallography revealed their detailed structure. Biological tests revealed 
mite, nematode, chytrid and plasmodiophorid vectors, MLOs were distinguished from plant viruses, and viroids were discovered. Proof of the infectivity of viral RNA and DNA, followed by sequencing of complete viral genomes, allowed their genes and control elements to be defined. Although some viral genomes were monopartite and others multipartite, each typically encoded proteins involved in replication, movement within the plant, particle production and, commonly, transmission by vectors. The processes involved in transmission, viral replication and symptom production, and the roles of gene silencing, were then studied intensively. Genetic variability was analyzed and short-term evolution explored. A soundly based taxonomy was devised and now embraces over 70 virus genera and 800 species. Virus ecological and epidemiological research led to schemes for producing virus-tested stocks of vegetatively propagated plants, quarantine regulations, application of vectorcontrolling chemicals to crops and use of virus-resistant cultivars that contain conventional or man-made resistance genes. These and other changes in agricultural practices have resulted in substantial increases in crop yields and food security. Since about 1950, results of research on viruses infecting hosts of any kind have been integrated to constitute virology, with plant virology contributing many seminal discoveries. The biological phase of plant virology has progressed to molecular biological and molecular genetic phases, and plant viruses have become tools in molecular biology, cell biology and biotechnology.

Plant virus structure by X-ray diffraction and electron microscopy. G. Stubbs, S. Baumgarten, W. Bian, A. Kendall, M. McDonald, and S. Ghabrial. Vanderbilt University, Nashville, TN. Phytopathology 98:S194.

Plant virus structures have been studied by X-ray diffraction since the pioneering studies on the filamentous tobacco mosaic virus (TMV) and potato virus $\mathrm{X}$ (PVX) and the icosahedral tomato bushy stunt virus (TBSV) by Bernal and Fankuchen in the 1930s. The first virus electron microscopic studies, also of TMV, were published in 1939. Both methods were used in the 1950s and 1960s to determine the symmetry and dimensions of numerous icosahedral and filamentous viruses; X-ray studies of icosahedral viruses were by crystallography, of filamentous viruses by fiber diffraction. The first high resolution molecular models were described in the 1970s: TBSV by X-ray crystallography and TMV by fiber diffraction. Since that time, many icosahedral plant virus structures have been determined crystallographically at high resolution. Although structures of several tobamoviruses followed that of TMV, other filamentous virus structures have been more difficult; even helical symmetry determination has presented problems. We have combined cryo-electron microscopy and X-ray fiber diffraction to determine low resolution structures of the potexvirus PVX from the family Flexiviridae and the potyvirus soybean mosaic virus from the family Potyviridae, demonstrating a remarkable degree of structural similarity.

The beginnings of immunochemistry at the intersection of early plant virus research. P. H. Berger and P. J. Shiel. USDA-APHIS-PPQ Center for Plant Health Science and Technology, Raleigh, NC. Phytopathology 98:S194.

Advances in immunology over the last one and a half centuries has occurred in three distinct phases; the original medically oriented phase (1880-1910), the birth and advance of immunochemistry (1910-1960), and then a synthesis of earlier concepts to drive the current biological and medical orientation of the research. Early advances in the structure and chemical nature of plant viruses occurred parallel to those in immunochemistry, producing mutual and synergistic increases in knowledge for both disciplines. Serology was used for classification and detection of plant viruses even before techniques of virus purification and crystallization were used. In turn, the purification techniques used for plant viruses, including the use of sucrose density gradient centrifugation, facilitated advances in the characterization of serum proteins and their components. From this synthesis, a myriad of techniques have been developed to detect and study plant pathogens. A few of these past and current techniques, as well as promising new technologies will be highlighted. The fruits of these early efforts are still present, use of serological techniques for the detection and classification of plant pathogens is still one of the primary tools used by researchers and diagnosticians, with new technologies appearing at a rapid pace.

Virus movement and its spreading impact on plant biological research. $R$. S. Nelson. Samuel Roberts Noble Foundation, Inc., Ardmore, OK. Phytopathology 98:S194.

Viruses, as obligate organisms, rely on host factors to aid in their accumulation and movement throughout the host. In general, these host factors are part of a system whose primary function is to facilitate host macromolecule accumulation and movement. Thus, the study of virus movement has told us much about host macromolecule trafficking. This presentation will review the progress plant virologists have made in studying virus movement and the impact these findings have had on plant biological research. The presentation will begin with a review of studies on the functional characterization of viral movement proteins and how the findings increased our understanding of the host macromolecule cell-to-cell transport system. It will proceed through a review of our understanding of virus vascular transport and how this knowledge increased our understanding of the plant vascular system and its importance for RNA silencing. It will end with a description of current work studying intracellular virus movement and the emerging importance of these findings for understanding host macromolecule intracellular transport associated with membranes and cytoskeleton. Although much has been learned about host macromolecule movement using viruses as reporters, we only have modestly sampled their potential usefulness in this area.

Clearing the clouds of mystery: Myron K. Brakke (1923-2007). K.-B. Scholthof. Dept. Plant Pathology and Microbiology, Texas A\&M University, College Station. Phytopathology 98:S194.

Plant pathology lost a distinguished pioneer in plant virology, truly a giant in our field, when Myron K. Brakke died on 15 June 2007. Brakke was best known for his development of sucrose density gradient centrifugation for the purification and characterization of plant viruses as a research associate with Lindsay M. Black at the Brooklyn Botanic Garden in the early 1950s. As a career scientist with the USDA-ARS at the University of Nebraska-Lincoln in the Department of Plant Pathology, Brakke developed and refined the tools and techniques that were crucial for progress in elucidating the physicochemistry, biochemistry and biology of viruses. In addition to discussing his development of sucrose density gradients, Brakke's contributions to our understanding of insect-vectored plant viruses, zoospores as agents of plant virus infection, and his work on aberrant ratio induced by virus infection of maize will be summarized. In many cases returning to the original literature from Brakke's half-century of service to agriculture and plant pathology provides fresh insight into his ideas and the development of the now routine tools and techniques of virology. Those readings reveal the measure of Brakke's success in using biochemistry and biology, as he wrote, to clear "the clouds of mystery" in plant virology.

\section{Protein Modifications During Host/Pathogen Interactions}

Functional conservation of the U-box/ARM E3 ligase SPL11-mediated cell death and defense pathway in rice and Arabidopsis. G.-L. Wang. Ohio State University, Columbus, OH. Phytopathology 98:S194.

Emerging evidence suggests that ubiquitination-mediated protein degradation plays an important role in plant programmed cell death (PCD) and plantmicrobe interactions. To investigate the role of PCD in the defense response to pathogen invasion, we characterized the lesion mimic mutant spll1 and cloned the Spl11 gene via a map-based cloning strategy. The predicted SPL11 protein contains a U-box domain and an armadillo (ARM) repeat domain, which were demonstrated in yeast and mammalian systems to be involved in ubiquitination and protein-protein interactions, respectively. In vitro ubiquitination assays indicated that the SPL11 possesses E3 ubiquitin ligase activity that is dependent on an intact U-box domain. In searching for other components involved in the Spl11-mediated signaling pathway, eight different SPL11-interacting proteins (SPINs) were identified in yeast two-hybrid screenings. In vitro GST binding assay confirmed the interaction between
SPL11 and SPIN1 (RNA-binding protein), SPIN3 (MOM-like protein) and SPIN6 (Rho-GTPase protein). RNAi and overexpression lines of these genes are being characterized for their alterations in defense responses to rice pathogens. Four suppressors of the spll1 mutant phenotype have been identified from screening of 7,000 EMS-mutagenized M2 lines. The suppressor genes are being mapped using F2 populations. Interestingly, we identified a TDNA insertion mutant of the Arabidopsis Spl11 ortholog which displays accelerated cell death and stunted growth phenotypes. The Arabidopsis mutant, named Atspl11, conferred enhanced resistance to the bacterial pathogens Pseudomonas syringae pv. maculicola (Psm ES4326) and Xanthomonas campestris pv. campestris (Xcc 33913), and the fungal pathogen Golovinomyces cichoracearum (UCSC1). RT-PCR analysis indicated that the $P R 1$ gene is highly induced and the PDF1.2 gene is highly suppressed in the mutant. In vitro E3 ubiquitination assay showed that AtSPL11 has ubiquitin ligase activity. These results demonstrate that the function of the Spl11 gene in suppressing plant cell death and activating defense response is conserved between monocots and dicots. Acknowledgements: This project is supported by the USDA-CSREES's National Research Initiative (NRI) (\#2007-01667). 
ADP-ribosylation and host-pathogen interactions. L. Adams-Phillips. University of Wisconsin, Madison, WI. Phytopathology 98:S195.

Poly(ADP-ribosyl)ation is a post-translational modification in which ADPribose polymers are attached to a protein. In mammalian systems, poly(ADPribosyl)ation is well known for its role in DNA repair and transcriptional regulation as well as impacts on ischemia and apoptosis. In plants, recent evidence has indicated a role for poly(ADP-ribosyl)ation in responses to abiotic stresses such as drought and high light, but no role had been shown for responses to biotic stresses. We initially hypothesized a role for poly(ADPribosyl)ation in plant defense responses when we detected the up-regulated expression of ADP-ribosylation-related genes upon infection with avirulent Pseudomonas syringae pv. tomato (Pst). Upregulation is also observed after infection with Botrytis cinerea and upon treatment with flg22, a bacterial flagellin-derived elicitor of innate immune responses. Upon pathogen infection, we find that levels of ADP-ribose polymer increase moderately and ADP-ribosylation of discrete proteins is observed. We and others have found that Arabidopsis carrying a gene knockout in a putative ADP-ribose pyrophosphatase exhibits altered defense responses. Of equal or greater significance, pharmacological inhibitors of poly(ADP-ribose) polymerase (PARP) perturb some but not all FLS2-mediated responses (e.g. callose deposition, seedling growth inhibition, and oxidative burst). Additional studies with ADP-ribosylation-related gene knockout and overexpression plants will be discussed.

Molecular and cellular characterization of the Arabidopsis SON1 F-box factor. B. St-Pierre. University of Vermont, Burlington, VT. Phytopathology 98:S195.
Genomic analyses have revealed that F-box factors represent one of the largest protein families in Arabidopsis thaliana and in rice (over 600 predicted members in each species), suggesting that selective proteolysis mediated by SCF-type ubiquitin E3 ligase complexes represents an important regulatory process in plants. Our lab has previously described the putative F-box factor SUPPRESSOR OF nim1-1 (SON1) as a regulator of disease resistance in Arabidopsis. Interestingly, SON1 is a member of the largest subfamily of plant F-box factors, which share, in addition to the F-box region, conserved plant-specific regions of unknown structure and function. To gain more insight into its biological role, we are currently characterizing the function of SON1 at the cellular and the molecular levels. First, we are analyzing the tissue accumulation of SON1 mRNA and protein in Arabidopsis. Secondly, we have created transgenic Arabidopsis plants that express SON1 as a translational fusion with green fluorescent protein (GFP) to identify the cellular compartment where SON1 activity occurs. Finally, we are searching for SON1-interacting proteins using yeast-2-hybrid screens as well as cosedimentation assays from Arabidopsis tissue extracts. Interacting proteins identified by these approaches represent candidate ubiquitylation substrate or regulatory factors that will reveal important clues on the nature of the molecular pathway(s) affected by SON1. Together, these investigations will lead to a better understanding of the biological role(s) of SON1 by providing essential basic information on histological distribution, subcellular localization and molecular interactions. To our knowledge, they also represent the first experimental characterization of a novel F-box-associated domain shared by hundreds of plant proteins.

\section{Resistance Genes-Past, Present, and Future}

The role of plant resistance genes in activating defense responses at the host-pathogen interface. S. Xiao. Center for Biosystems Research, University of Maryland Biotechnology Institute. Phytopathology 98:S195.

Plant resistance genes play important roles in crop protection. During invasive growth of the pathogen pathogens use effector proteins to suppress microbeassociated molecular pattern (MAMP)-triggered immunity in plants, resulting in plant diseases. To counter pathogen suppression, plants have evolved disease resistance $(\mathrm{R})$ proteins to detect the presence of pathogen effectors and activate $\mathrm{R}$ gene-dependent, multifaceted defense systems. Most isolated $\mathrm{R}$ genes encode proteins with a leucine-rich-repeat (LRR) domain, of which the majority also contain a nucleotide-binding site (NBS) domain. Two basic models have been proposed for specific recognition of pathogen effectors (termed Avr factors encoded by the avirulence genes) by corresponding $\mathrm{R}$ proteins. To date, both direct and indirect R-Avr interactions have been demonstrated in several hostpathogen interactions. It is believed that upon recognition, $\mathrm{R}$ proteins are activated by mechanisms including changes of conformation and/or subcellular localization. The atypical R gene RPW8 from Arabidopsis encodes a protein that is unique in structure and confers broad-spectrum resistance to powdery mildew. We demonstrated recently that RPW8 functions at the hostpathogen interface through a highly conserved salicylic acid-dependent signaling pathway. Future directions of $\mathrm{R}$ gene research will be discussed.

Identification and characterization of soybean rust resistance in Plant Introductions from the USDA's soybean germplasm collection. D. R. WALKER (1), R. L. Nelson (1), G. L. Hartman (1), B. Buckley (2), S. Moore (3), R. W. Schneider (4), D. Weaver (5), E. Shipe (6), J. Mueller (7), and H. R. Boerma (8). (1) USDA-ARS, Soybean/Maize Germplasm, Pathology and Genetics Unit, Urbana, IL; (2) Louisiana State University AgCenter, Bossier City, LA; (3) Louisiana State University AgCenter, Alexandria, LA; (4) Louisiana State University AgCenter, Baton Rouge, LA; (5) Auburn University, Auburn, AL; (6) Clemson University, Clemson, SC; (7) Clemson University, Blackville, SC; (8) University of Georgia, Athens, GA. Phytopathology 98:S195.

Identification of soybean germplasm accessions with resistance to Phakopsora pachyrhizi is the first step in the development of cultivars with effective and durable resistance to soybean rust. Resistance can involve a hypersensitive response, the development of reddish-brown instead of tan lesions, and/or other host responses that slow the development of the pathogen and the disease. In a 2007 collaboration involving several different institutions, the reactions of 293 to 403 Plant Introductions (PIs) from maturity groups (MGs) $000-\mathrm{X}$ were evaluated at seven locations in five states in the Southeastern U.S.A. Late planting dates and the use of artificial lighting to extend the photoperiod at some sites helped to synchronize plant maturity with the fall rust epidemic. Depending on the location, lines were rated for disease incidence and severity, lesion or uredinia density, and amount of sporulation, often with the help of a microscope. Approximately 85 of the PIs showed high to moderate resistance to rust at two or more locations. The Rpp1 gene conferred immunity to the local isolate at all locations, while Rpp2, Rpp3, and Rpp?(Hyuuga) reduced severity and sporulation at most locations. The reactions of other accessions with unknown resistance genes ranged from apparent immunity to reduced severity and/or sporulation relative to susceptible cultivars with similar maturities. The data obtained from these collaborative evaluations provide North American soybean breeders and pathologists with additional guidance in selecting parents for crosses and in deciding which lines to include in other experiments.

Next generation genetic analysis of plant pathogen interactions. K. S. Caldwell, L. McHale, H. van Leuwen, O. Ochoa, T. Wroblewski, A. Kozik, M.-J. Truco, and R. W. Michelmore. The Genome Center and Department of Plant Sciences, University of California in Davis, Davis, CA. Phytopathology 98:S195.

The past decade has seen significant advances in elucidating the molecular bases of plant pathogen interactions; however, this has been on a gene-bygene basis. The arrival of new, cost-efficient, high-throughput, sequencing and genotyping technologies provide a platform for amassing a wealth of intra- and inter-specific data that will lead to the rapid identification and detailed characterization of many genes involved in resistance. Microarray and Single Nucleotide Polymorphism detection technologies allow a shift from single marker assays to massively parallel genotyping. Candidate genes can be mapped relative to resistance phenotypes to identify genes determining resistance as well as targets of pathogen effectors. These markers can subsequently be utilized for marker assisted selection to accelerate the introgression of resistance. Parallel genomic studies on pathogens will provide an understanding of the molecular basis of specificity and the opportunity to select targets for more durable resistance. We are using high throughput sequencing and genotyping technologies to gain a detailed understanding of the global architecture of disease resistance in lettuce.

\section{Plant Disease Management}

\section{Citrus Canker: A Case Study in Regulatory Plant Pathology; Past, Present, and Future}

The changing face of regulatory plant pathology. N. K. Osterbauer. Oregon Dept. of Agric, Salem, OR. Phytopathology 98:S195.
In 1912, the U.S. adopted the Plant Quarantine Act. This was the U.S.'s first legal action taken to prevent the introduction of foreign plant pests. Other laws aimed at excluding plant pests quickly followed. Today, the USDA Animal and Plant Health Inspection Service (APHIS) is responsible for enforcing these laws. The laws have allowed APHIS to establish inspection 
stations at ports of entry, adopt quarantines, inspect agricultural goods, and restrict entry of infested goods. If a pest slips through this line of defense, APHIS works with state governments on domestic quarantines to limit spread and on survey and eradication plans for newly introduced pests. In recent years, the number of invasive pests introduced to the U.S. has increased, suggesting the traditional regulatory tools of pest exclusion are becoming less effective. This increase is associated with increases in world trade and the spread of invasive pests across international borders. In response, APHIS and state regulators are investigating new tools for providing protection from invasive pests. These tools place greater onus on industry to prove their products are pest-free before sale. In general, an industry adopts a systems approach that protects products from becoming infected prior to shipment. Although quarantines, border inspections, and surveys will continue to be important regulatory tools, the industry-based systems approach holds great promise for the future of pest exclusion.

Historical overview of the citrus canker eradication program. T. S. Schubert. Florida Dept. of Agric \& Con Serv, Gainesville, FL. Phytopathology 98:S196.

Asiatic citrus canker disease caused by Xanthomonas axonopodis pv. citri has successfully established at least three times in Florida, the last episode commencing in August 1995 in suburban Miami-Dade County, Florida. Previous introductions, one around 1910 and a second in 1986 were effectively eradicated. Efforts to eradicate the third introduction have been officially discontinued as of January 2006. Several factors contributed to the failure of the last eradication effort, namely (1) a lack of timely funding; (2) lack of cooperation from a small proportion of residential non-commercial citrus growers; (3) legal challenges (again almost entirely from the residential sector) to many aspects of the regulatory program resulting in delays in implementation; and finally (4) a series of catastrophic tropical storms that spread the disease too widely for successful eradication. Citrus canker is now managed using integrated techniques, and is being supplanted as the worst citrus disease in Florida by Huanglongbing / citrus greening, caused by Candidatus Liberibacter asiaticus, a non-eradicable systemic bacterial disease transmitted by the Asian citrus psyllid Diaphorina citri. Both the pathogen and vector of Huanglongbing are introduced exotic plant pests, discovered in residential, non-commercial citrus also. Recent events in Florida citriculture present another challenging facet of the urban-rural interface of American agriculture.

Science-based regulatory decisions. T. R. Gottwald. USDA ARS USHRL, Ft. Pierce, FL. Phytopathology 98:S196.

Florida has endured three citrus canker (CC, caused by Xanthomonas citri ssp. citri) epidemics over the last 100 years. The most recent joint State/Federal Citrus Canker Eradication Program (CCEP) ended in 2006 after 10 yrs and a total cost of $\$ 1$ billion. Although the press and a few outspoken residents claim it was a failure, it was not. The program held off $\mathrm{CC}$ and gave the citrus industry freedom from statewide quarantines and national/international marketing restrictions for those $10 \mathrm{yrs}$. Since then, CC has greatly increased production costs, and caused loss of fresh fruit markets. The operational basis of the CCEP was a series of science-based regulatory decisions: 1) The 1900- $\mathrm{ft}$ law, based on a research study of spread of CC in over 19,000 trees in south Florida and required removal of all 'exposed trees' within 1900ft (579m) of a diseased tree. 2) The sentinel tree survey, based on the minimal distances of spread that set up a recurring survey within residential areas. 3) Following the hurricanes of 2004, a targeted survey, based on the direction spread of CC during hurricanes, was used to find and eliminate new infections. 4) Georeferenced hurricane modeling was used to estimate the spread of $\mathrm{CC}$ from known existing infections due to hurricane Wilma in 2005 that estimated continued eradication would require removal of $169,700 \mathrm{ac}(68,675 \mathrm{ha})$ of commercial citrus, $25.7 \%$ of the remaining industry, an unacceptable amount, and led to the end of the program in 2006.

Best management practices post eradication. J. Graham. UF IFAS CREC, Lake Alfred, FL. Phytopathology 98:S196.

In the aftermath of an unsuccessful eradication program, citrus canker (CC) quickly became established throughout southern Florida. The statewide quarantine in August 2006 had an immediate impact on fresh fruit movement. Presently, shipment of all citrus produced in Florida to citrus-producing states is prohibited. Key goals are to demonstrate that current disinfection protocols greatly reduce pathogen survival on fruit surfaces, and that grove and packinghouse inspections can keep symptomatic fruit out of packed cartons. Argentine experience indicates that $>5 \%$ infected fruit in a block creates an unacceptable risk for harvest aimed at fresh markets. In southern Brazil and northeast Argentina integrated programs are profitably employed to prevent and control CC in moderately susceptible sweet oranges and tangerines sold as fresh fruit in both internal and export markets. These production areas have established windbreaks and utilized more field resistant cultivars. Multiple copper sprays protect fruit from infection and insecticide sprays are required for control of citrus leafminer to reduce exacerbation of infection on leaves. In Florida, a highly effective CC management system is not yet in place for grapefruit, the most susceptible fresh fruit variety.

Future challenges in regulatory plant pathology and health management programs. P. J. Gomes. USDA APHIS PPQ-EDP, Raleigh, NC. Phytopathology 98:S196.

Citrus canker, citrus greening and other exotic plant pathogens will continue to pose serious challenges to Federal, State and local regulatory agencies. Those challenges include: 1.) Additional plant pathogens and/or their vector(s) of quarantine significance very likely will be introduced -- most likely into residential and other high risk areas, 2.) Knowledge regarding what to regulate will not always be clear, 3.) Diagnostic methods will be needed to detect diseases prior to symptom expression, 4.) New tools or treatments (therapies) are needed to prevent, contain, control or eradicate infections caused by regulated plant pathogens, 5.) Greater awareness of threats and consequences posed by plant pathogens and/or their vector(s) needs to be conveyed to the general public and farmers, 6.) Identifying pathways that plant pathogens and their vector(s) can enter the U.S. or move Interstate and assessing related risks, 6.) Legal challenges to regulatory actions can be expected to continue, 7.) Demands for compensation can be expected by those affected by regulatory actions, and 8.) Establishing international cooperation to find collaborative solutions will be needed.

\section{Phytophthora: A Global Problem with Continued and Historical Importance}

A historical review of Phytophthora diseases. E. Hansen. Department of Botany and Plant Pathology, Oregon State University, Corvallis, OR. Phytopathology 98:S196.

In many ways Phytophthora has defined the science, the practice, and the promise of plant pathology, from the potato famine to the new world of pathological genomics. Phytophthora infestans spawned plant pathology and thrust it onto the world stage, and in 2007, more articles in the APS journals Phytopathology and Plant Disease addressed Phytophthora than any other genus of plant pathogens. Our understanding of pathogenesis has been enhanced by work with Phytophthora phytoalexins and elicitins, and now with complete genome sequences for 4+ species available, Phytophthora will continue to lead the way in genomics research in plant pathology. Phytophthora provided early and dramatic examples of the importance of nomenclature, taxonomy, and today phylogenetics to plant pathologists. Phytophthora first demonstrated the dangers of invasive pathogens through the globalization of agriculture, and continues to force the issue as newly recognized exotic Phytophthora species threaten wild as well as agricultural ecosystems. Phytophthora species have been instrumental for epidemiological research and the development of disease forecasting models. It's not all about potatoes and peppers, either. Phytophthora ramorum, described only 7 years ago, now leads the annual Phytophthora citation index. The history of Phytophthora and the diseases it causes is the history of plant pathology, and today's research on Phytophthora gives a preview of the directions plant pathology will take in the future.

Phytophthora infestans: A challenging case study for the field of plant pathology. N. J. Grunwald. USDA ARS, Corvallis, OR. Phytopathology 98:S196.

The science of plant pathology was born with the emergence of the potato late blight pathogen Phytophthora infestans. This pathogen caused several years of severe potato late blight epidemics in the 1840s resulting in the Irish potato famine as well as large demographic shifts in both Europe and the U.S. due to migration from Ireland. Potato late blight continues to be the most important potato pathogen worldwide and is of particular importance to growers in the highland tropics. $P$. infestans is one of the best understood plant pathogens and serves as a model organism for most research on other Phytophthora pathogens. We have a clear understanding of the evolutionary history, epidemiology, genetics, and host-pathogen coevolution; yet, management remains a challenge. Recent major developments include the availability of the whole genome sequence as well as the discovery of a large superfamily of effector proteins that provide new opportunities. The real question, however, is whether the next decades of research can provide novel tools for disease management. 
Phytophthora capsici: A serious threat to vegetable industries in the world. M. Babadoost. University of Illinois, Urbana, IL. Phytopathology 98:S197.

Phytophthora capsici Leonian was first described on peppers in New Mexico in 1922. Subsequently, it was reported on more than 50 plant species in 15 families. Among the affected plants, cucurbits and peppers are the most susceptible hosts. In the past 10 years, $P$. capsici has been reported from many vegetable growing areas throughout the world, causing up to $100 \%$ crop losses. P. capsici can infect plants at any growth stage, causing a range of symptoms including root rot, stem lesions, leaf spot, and fruit rot. Variation in genetics and virulence among isolates of $P$. capsici has been reported from different parts of the world, which makes management of the pathogen very challenging. $P$. capsici is a soil-borne pathogen and can survive in the soil for more than three years. $P$. capsici also spreads by air movement. There is limited information about biology of $P$. capsici and epidemiology of the diseases caused by this pathogen. There is no single method with adequate control measure against this pathogen. Integrated approaches of cultural practices and chemical application are used to minimize crop losses by $P$. capsici. Regional, national, and international efforts are needed to carry out comprehensive studies on epidemiology of the diseases caused by $P$. capsici and develop effective strategies for management of P. capsici.
Phytophthora ramorum: A recent discovery with a large impact. D. M. Rizzo. University of California, Davis, CA. Phytopathology 98:S197.

Phytophthora ramorum first came to attention of the plant pathology community as the causal agent of sudden oak death (SOD). Since 1994, potentially millions of tanoak (Lithocarpus densiflorus) and oak (Quercus spp.) have been killed by this pathogen in coastal forest of California and Oregon. P. ramorum is a generalist and has a host range of well over 100 species ranging from ferns to conifers to herbaceous plants and shrubs. On these hosts, $P$. ramorum causes a variety of foliar and branch symptoms. Since its association with SOD in 2000, much research has been conducted on the biology, genetics (including the sequencing of its genome), epidemiology, host-pathogen interactions and ecological impacts of P. ramorum. This talk will put $P$. ramorum research and management into historical context though examination of past research on other forest Phytophthoras and subsequent impacts of $P$. ramorum research on other Phytophthoras. Research on $P$. cinnamomi, $P$. lateralis and European Oak decline set the stage for early research on $P$. ramorum and set the stage for many discoveries concerning SOD. The potential importance of the nursery trade for long distance movement of $P$. ramorum has led to the implementation of national and international regulations and quarantines. This in turn resulted in numerous surveys and monitoring programs for the presence of $P$. ramorum. In the course of these surveys, many new Phytophthoras have been discovered in natural ecosystems and nursery settings.

\section{Professionalism/Service/Outreach}

\section{Building International Bridges in a Flat World}

Adapting to a flat world. L. Calvert. CIAT, Cali, Colombia. Phytopathology 98:S197.

Thomas Friedman's book "The World is Flat" helps to explain some of the changes that are occurring as communication technologies have become global. Beginning with the premise that a major driving force is globalization, this symposium will highlight some of the changes that are occurring in Plant Pathology throughout the world. In the 1960s, the emphasis was on increasing food production for the developing countries, and this has gradually changed to poverty alleviation through income generation for farmers. With increased global trade in agricultural products, invasive plant pathogens are becoming more of a problem. New markets for plants that produce bio-fuels will increase the price of food, which is accelerating the trend towards crop intensification. As farmer plant higher value crops, often there is a decrease in the genetic diversity that can make their crops more susceptible to epidemics of pests and diseases. Food security and development of export markets has encouraged many countries to improving their agricultural infrastructure, and new programs in plant pathology are being offered in their universities. The management of information is becoming more critical as genomes and the function of their genes become better characterized. Global networks with information on plant pathogens are becoming our communities of practice. Multitasking in cyberspace will be the norm for the next generation of plant pathologists as multidisciplinary teams work together to solve critical needs for food production. As plant pathologists, we need to be aware of the trends in agriculture and the challenges and opportunities that are present in a world that is rapidly changing.

Plant pathology in Latin America; Building bridges throughout the world. O. A. Moreno-Valenzuela and M. Juanqui-Valencia. UBBMP-CICY, Merida, Yucatan, Mexico. Phytopathology 98:S197.

Last year, the world population increased by 77 million and the global population is expected to grow to over 9 billion by the middle of the 21 st century. More than $95 \%$ of that growth is occurring in the developing countries, where the pressure on land and water resources is already intense. If we are to continue to meet the demands for agricultural products, new agricultural technologies that improve yields and mitigate adverse factors including plant diseases will need to be implemented. The Organization for Economic Co-operation and Development (OECD) states that "the transfer of technology to developing countries is a key element so that countries can develop their own research and development infrastructure and capabilities to meet their own needs". Collaboration of industry, research institutions, and universities both in developed countries and developing countries is needed to reach the goals set by the OECD for the efficient production of food. LatinAmerica has established collaborations with many countries throughout the world and these include both basic and applied projects that involve plant pathology. Still, Latin-America contributed only 3\% of the scientific articles published that were published from 1996 though 2005. Strategies to increase the scientific infrastructure and production in Latin American need to be implemented. Potato, maize, and wheat are three of the most important food crops in the world and serve as examples of how different institutions in Latin America are collaborating to solve production constraints caused by important diseases of these crops. The International Potato Center (CIP) and the International Maize and Wheat Improvement Center (CIMMYT) are examples of institutions which participate in an extensive global network of people and organizations involving near one hundred countries. The international cooperative potato late blight program (PICTIPAPA) was established in Mexico to facilitate and conduct potato late blight research and to promote more sustainable potato production systems. In Mexico, there are many universities and research centers, which work on different aspects of plant pathology. At least nineteen groups are working on plant virology, studying different viruses, their molecular interaction with the plant, molecular characterization, and biodiversity. These groups have projects that involve the collaboration of laboratories from different countries, with the participation of postgraduate students. The importance of establish and reinforce collaborative programs related to plant pathology throughout the world will be discussed.

Biosciences research and capacity building in east and central Africa. $S$. Kelemu. Research Director, BecA-ILRI Platform, Intl Livestock Research Inst, Nairobi, Kenya. Phytopathology 98:S197.

Agriculture is the most important sector in the economies of most African countries. Agricultural biotechnology will contribute to finding solutions to production and environmental constraints globally. The application of molecular biology tools has greatly enhanced our ability to diagnose diseases, determine the genetic diversity of plants, animals and pest populations, understand host-pathogen interactions; understand and localize genes for important agronomic traits, and combine genes from a wide array of organisms in transgenic technologies and develop durable strategies for the management of biotic and abiotic stresses. The challenge is, thus, to make use of new developments in the biosciences to reduce poverty and create wealth in Africa in sustainable and equitable ways. Biosciences east and central Africa (BecA) is an agricultural biotechnology initiative developed in the framework of Centres of Excellence for Science and Technology. BecA aims to employ modern biotechnology to improve agriculture in eastern and central Africa. It also seeks to strengthen the capacity of scientists in eastern and central Africa to conduct bioscience research and to significantly contribute to improved products that can enhance livelihoods of farmers in the region. BecA has a hub with a state of the art shared biosciences facility located on the campus of the International Livestock Research Institute (ILRI), Nairobi, Kenya, that provides a research platform, research-related services and capacity building opportunities. A critical mass of scientific capacity in plant, microbial and animal biotechnology is developing at the BecA hub through various national, regional and international partnerships, in order to ensure that scientific advances are readily available to the African scientific community. The role of BecA in molecular tool applications and capacity building to address agricultural related problems of importance for alleviating poverty and promoting development in Africa will be discussed. 
Plant pathology in a changing world. Y.-L. Peng (1) and L. Guo (2). (1) President Chinese Society for Plant Pathology, Prof. Department of Plant Pathology, China Agricultural University, Beijing, China; (2) Feng Feng, the National Science Foundation of China, Beijing 100085, China. Phytopathology 98:S198.

Since China has 1.3 billion people, food security is a very important concern. To maintain food self-sufficiency during a time that crop-land is declining due to rapid urbanization and industrialization is a major challenge for the Chinese government. To insure the food security, more research funding from diverse resources was recently set up. For example, in 2007, the central government provided a special fund of one billion RMB for the start-up of ten programs aimed at solving technology restrains to the increase the production of ten major agricultural crops, including rice, corn and wheat. Forty more programs are planed in the next four years. In each of these programs, technologies related to plant protection are highly demanded. In addition, there were nine special projects started with a budget of 10 million RMB, that target the control of especially important crop diseases. The Ministry of Science and Technology and the National Science Foundation of China also provide funding for basic research on plant pathology. To encourage the international exchange and collaboration, each of the research programs and projects includes budget for international collaborations. Special funds from the China Scholarship Council and from the National Science Foundation of China have also been set up to support the student and visiting scientist exchange program and the international collaboration, respectively. Details of future opportunities for international cooperation will be discussed.
Building bridges for international agricultural research: Reflections on experiences past, present, and future. R. J. Nelson. Program Director, The McKnight Foundation Collaborative Crop Research Program and Associate Professor, Plant Pathology \& Plant-Microbe Biology and Plant Breeding \& Genetics, Cornell University. Phytopathology 98:S198.

Agricultural researchers in developing countries are often disadvantaged by resource constraints, limited opportunities for scientific interaction, and a lack of incentives. A variety of programs have been designed to overcome these limitations by building bridges between national research systems and relatively well-resourced institutions with the aim of fostering research for development. Among these is the Collaborative Crop Research Program (CCRP), established by The McKnight Foundation in 1994. Through several cycles of grant-making, the CCRP has taken an experimental approach to grant-making with the aim of improving food security for resource-poor rural people. The program initially funded north-south partnerships, then moved towards more complex research-development collaborations, and currently supports clusters of projects with shared geographic and agroecological foci. While the initial set of grants targeted specific production constraints, such as disease and insect problems of particular crops, the program has evolved towards a food systems approach, in which the wider complex of factors affecting food insecurity are taken into consideration. Lessons learned about program and project design, impacts and sustainability will be presented. In addition, current aspirations, opportunities and challenges, will be discussed from the perspectives of researcher and donor representative.

\section{Teaching Plant Pathology: Ideas and Tools for Today's Classrooms}

Looking in, reaching out: Mainstream microbes. G. W. Hudler. Cornell University, Plant Pathology, Ithaca, NY. Phytopathology 98:S198.

Over the last 17 years more than 4000 students have taken "Magical Mushrooms, Mischievous Molds" at Cornell University. I will attempt to share my personal recipe for success in teaching and maintaining a consistently large enrollment, using this class as an example. A few key tactics I have found that often brings a sparkle to students' eyes include: (1) Aim high, put myself in the audience, and shoot low (2) Know my material, (3) Organize my message, (4) If I can't see it, I don't show it, (5) Take risks to get rewards, and (6) Smile. It's a short list but it's one that has worked throughout the time that I have been sharing my enthusiasm with those who have not yet discovered that sick plants and healthy pathogens are worth caring about. In the end, the overall goal for successful teaching is to have students leave the class comfortable with the notion that they can learn more on their own and thus, will want to be lifelong learners.

New approaches for teaching: Focusing on learning outcomes. D. M. Eastburn. University of Illinois, Crop Science, Urbana, IL. Phytopathology 98:S198.

Most instructors today were educated in classes where a teacher-centered lecture was the primary method of instruction. As a result, many of us teach our courses using this same model, with the teacher as the distributor of knowledge and the students as passive recipients. Education research, however, indicates that other models of instruction result in increased levels of comprehension and application of information by students. Concepts such as student-centered learning, active learning, problem-based learning, and peerto-peer teaching involve the students as active participants in the learning process. With these methods, the role of the instructor shifts to that of a facilitator of learning. An aspect of the teaching process that is often lacking in instruction is critical evaluation of learning outcomes. Research has shown that students can do well on exams without truly understanding the concepts. A way to address this problem is to teach backward: start with a list of desired learning outcomes and then work backward to design instructional strategies. The outcomes go beyond an expectation that students will be able to parrot back information on an exam. There should be an expectation that students will apply their knowledge in relevant situations. If instructors know what they want the students to be able to "do" as a result of learning the material, then it becomes easier to design methods to evaluate whether the students have met those expectations.

Utilizing technology to enhance teaching effectiveness and shape new curricula. H. D. SHEW (1), C. A. Gallup (1), and A. T. Robertson (2). (1) North Carolina State University, Plant Pathology; (2) North Carolina State University, DELTA, Raleigh, NC. Phytopathology 98:S198.

Integration of new technologies into the classroom has become expected of all undergraduate instructors. This technology usually begins with the development of an effective website for your course and progresses to more complex and advanced types of technology. However, selection of the appropriate technology for your class and curriculum can be an intimidating, if not daunting, task. With new or updated technologies streaming endlessly to the marketplace, how do you decide what to use and how to use it? We will explore how we have addressed this issue in an undergraduate plant pathology class at N. C. State University. The key to selecting technologies is to choose those that are compatible with your teaching style so that you can best accomplish your teaching goals. Technology and teaching can be very effectively integrated, but technology should always be viewed as a tool that allows you the maximum freedom to be an effective teacher within the context of our rapidly changing educational system. Our discussion will include technologies for enhancing the experience of on-campus students as well as those that serve distance education students. Specifically, we will look at flash-based tools such as a glossary and flash cards, animations with embedded streaming video, fully immersive 3-D environments that are based on game-theory, and the promise of new game theory and virtual 3-D environments where students can interact on projects and lab experiments. 